University of Wollongong

Research Online

Faculty of Engineering and Information

Faculty of Engineering and Information

Sciences - Papers: Part A

Sciences

$1-1-2014$

\title{
Effects of hydrogen on the critical conditions for dynamic recrystallization of titanium alloy during hot deformation
}

Jingwei Zhao

University of Wollongong, jzhao@uow.edu.au

Hua Ding

Northeastern University

Zhengyi Jiang

University of Wollongong, jiang@uow.edu.au

Dongbin Wei

University of Technology Sydney, dwei@uow.edu.au

Kezhi Linghu

Shougang Research Institute of Technology, kezhi@uow.edu.au

Follow this and additional works at: https://ro.uow.edu.au/eispapers

Part of the Engineering Commons, and the Science and Technology Studies Commons

Research Online is the open access institutional repository for the University of Wollongong. For further information contact the UOW Library: research-pubs@uow.edu.au 


\title{
Effects of hydrogen on the critical conditions for dynamic recrystallization of titanium alloy during hot deformation
}

\begin{abstract}
Hot deformation tests were performed to study the flow behavior and microstructural evolution of a Ti600 titanium alloy with different hydrogen contents. The effects of hydrogen on the critical conditions for the initiation of dynamic recrystallization (DRX) were investigated. The DRX kinetics models of hydrogenated Ti600 alloy were developed, and the DRX volume fractions were quantified under different deformation conditions. The results indicate that the addition of proper hydrogen (no greater than $0.3 \mathrm{pct}$ ) benefits the decrease of both the critical stress and critical strain for the initiation of DRX. The critical stress and critical strain are dependent linearly on the peak stress and the strain to peak stress, respectively. The strain range from the initiation to the completion of DRX increases gradually with hydrogen in the hydrogen range of 0 to $0.3 \mathrm{pct}$, and a slightly decreased strain range is observed at the hydrogen content of 0.5 pct relative to that of 0.3 pct. The addition of large amounts of hydrogen ( 0.3 pct or greater) in Ti600 alloy induces incomplete DRX during hot deformation.
\end{abstract}

\section{Keywords}

hot, dynamic, effects, hydrogen, deformation, recrystallization, titanium, alloy, critical, during, conditions

\section{Disciplines}

Engineering | Science and Technology Studies

\section{Publication Details}

Zhao, J., Ding, H., Jiang, Z., Wei, D. \& Linghu, K. (2014). Effects of hydrogen on the critical conditions for dynamic recrystallization of titanium alloy during hot deformation. Metallurgical and Materials Transactions A: Physical Metallurgy and Materials Science, 45 (11), 4932-4945. 


\title{
Effects of Hydrogen on the Critical Conditions for Dynamic Recrystallization of Titanium Alloy During Hot Deformation
}

\author{
JINGWEI ZHAO, HUA DING, ZHENGYI JIANG, DONGBIN WEI, \\ and KEZHI LINGHU
}

\begin{abstract}
Hot deformation tests were performed to study the flow behavior and microstructural evolution of a Ti600 titanium alloy with different hydrogen contents. The effects of hydrogen on the critical conditions for the initiation of dynamic recrystallization (DRX) were investigated. The DRX kinetics models of hydrogenated Ti600 alloy were developed, and the DRX volume fractions were quantified under different deformation conditions. The results indicate that the addition of proper hydrogen (no greater than $0.3 \mathrm{pct}$ ) benefits the decrease of both the critical stress and critical strain for the initiation of DRX. The critical stress and critical strain are dependent linearly on the peak stress and the strain to peak stress, respectively. The strain range from the initiation to the completion of DRX increases gradually with hydrogen in the hydrogen range of 0 to 0.3 pct, and a slightly decreased strain range is observed at the hydrogen content of 0.5 pct relative to that of 0.3 pct. The addition of large amounts of hydrogen $(0.3 \mathrm{pct}$ or greater) in Ti600 alloy induces incomplete DRX during hot deformation.
\end{abstract}

DOI: $10.1007 / \mathrm{s} 11661-014-2448-1$

(C) The Minerals, Metals \& Materials Society and ASM International 2014

\section{INTRODUCTION}

THERMOHYDROGEN treatment (THT) is a special processing technology in which hydrogen is used as a temporary alloying element in titanium alloys with the purpose of improving their hot workability. ${ }^{[1]}$ In this approach, hydrogen is at first added into titanium alloys through different procedures and then, removed by vacuum annealing to be a safety level after hot working. ${ }^{[2]}$ Senkov and Jonas ${ }^{[3]}$ studied the hot deformation behavior of titanium-hydrogen alloys in air over the temperature range from $773 \mathrm{~K}$ to $1273 \mathrm{~K}\left(500{ }^{\circ} \mathrm{C}\right.$ to $\left.1000{ }^{\circ} \mathrm{C}\right)$ within the $\alpha,(\alpha+\beta)$ and $\beta$ phases fields, and found that hydrogen could be retained at temperatures up to $1253 \mathrm{~K}\left(980{ }^{\circ} \mathrm{C}\right)$ due to the formation of an oxidised film on the specimen surface. Our previous study indicated that hydrogen could be kept in titanium alloy in air even though the temperature was raised up to $1373 \mathrm{~K}\left(1100{ }^{\circ} \mathrm{C}\right) \cdot{ }^{[4]}$ Hydrogen alloying is, therefore, effective in titanium alloys within a wide range of temperatures, and a multitude of investigations has indicated that the addition of proper hydrogen can significantly reduce the flow stress and enhance the

JINGWEI ZHAO, Associate Research Fellow, and ZHENGYI JIANG, Professor, are with the School of Mechanical, Materials and Mechatronic Engineering, University of Wollongong, Wollongong, NSW 2522, Australia. Contact e-mail: jwzhaocn@gmail.com HUA DING, Professor, is with the School of Materials and Metallurgy, Northeastern University, Shenyang 110004, P.R. China. DONGBIN WEI, Senior Lecturer, is with the School of Electrical, Mechanical and Mechatronic Systems, University of Technology Sydney, Sydney, NSW 2007, Australia. KEZHI LINGHU, Engineer, is with the Shougang Research Institute of Technology, Shougang Group, Beijing 100043, P.R. China. Contact e-mail: jwzhaocn@gmail.com

Manuscript submitted November 23, 2013.

Article published online July 15, 2014 plasticity of $\alpha,{ }^{[5]}$ near- $\alpha,{ }^{[6,7]}$ and $(\alpha+\beta)^{[8]}$ titanium alloys during hot deformation.

Ti600 alloy is a recently developed near- $\alpha$ hightemperature titanium alloy which can serve stably at temperatures up to $873 \mathrm{~K}\left(600{ }^{\circ} \mathrm{C}\right)$ due to its excellent creep performance, high tensile strength, and super fatigue resistance at the service temperature. ${ }^{[9]}$ Ti600 alloy is particularly suitable for the manufacture of aerofoil blades and disks in the aviation and aerospace industries. From the perspective of industrial production, hot deformation is a very important operation employed to modify the required final microstructure and mechanical properties of Ti600 alloy. Due to the high resistance of deformation and narrow range of deformation temperature, however, it is more difficult to deform Ti600 alloy relative to other metals using conventional hot working processes. ${ }^{[10]}$ Interestingly, THT provides an alternative approach to effectively overcome such a problem. The use of hydrogen as a temporary alloying element has become an important issue for improving the hot workability of Ti600 alloy, and many attempts have been made to achieve this goal. ${ }^{[6,7,11-13]}$

Dynamic recrystallization (DRX) is an important phenomenon for controlling the microstructure and mechanical properties of metals under industrial hot processing operations. ${ }^{[14]}$ DRX is of great interest because it significantly impacts the high-temperature flow stress, microstructural evolution, and final properties of a material after processing. Determination of the critical condition for the initiation of DRX is of considerable importance in the modeling of industrial hot working processes. The occurrence of DRX is generally indicated by the appearance of a peak stress in the stress-strain curve in a simulation of metal forming. 
However, DRX is actually initiated before the strain that corresponds to the peak stress. ${ }^{[15]}$ The critical strain for the initiation of DRX could be determined by metallography. However, this method requires extensive sampling near the estimated critical strains under different strain rates and deformation temperatures. In order to solve such problem, relevant mathematical relations for predicting the critical condition for the initiation of DRX have been proposed by some researchers. These relations are mainly obtained based on the kinetics of static recrystallization ${ }^{[16]}$ or the dislocation density work hardening model ${ }^{[17]}$ and the calculations needed are relatively complex. These relationships are, therefore, difficult to be used directly by an industrial metallurgist without full comprehension of the scientific background. Alternatively, Poliak and Jonas $^{[15,18,19]}$ suggested identifying the initiation of DRX phenomenologically from the inflection point in the curve of strain-hardening rate $v s$ flow stress. This method requires little knowledge of the physical background of hot working processes and has an important practical advantage that it is much easier to use than other approaches. This phenomenological method has found a variety of applications in the determination of critical conditions for DRX of many kinds of materials including steels, ${ }^{[20,21]}$ and nickel, ${ }^{[15]}$ titanium, ${ }^{[22]}$ aluminum, ${ }^{[23]}$ and magnesium ${ }^{[24]}$ alloys. With regard to Ti600 titanium alloy after THT, however, there is no relevant publication available that addresses identifying the initiation of DRX, let alone a systematic investigation on the effects of hydrogen on the critical conditions for DRX.

This work aims to systematically investigate the effects of hydrogen on the critical conditions for DRX of a Ti600 titanium alloy during hot deformation. The flow behavior and microstructural evolution of this alloy with different hydrogen contents were analysed. The critical stress and critical strain for the initiation of DRX were determined based on the aforementioned phenomenological method. The kinetics models of DRX were developed, and the DRX volume fractions of Ti600 alloy were quantified under different hydrogen contents, stains, strain rates, and temperatures.

\section{EXPERIMENTAL PROCEDURE}

A Ti600 titanium alloy was used in this investigation. The chemical compositions (wt pct) of the alloy are 6 $\mathrm{Al}, 2.8 \mathrm{Sn}, 4 \mathrm{Zr}, 0.5 \mathrm{Mo}, 0.4 \mathrm{Si}, 0.1 \mathrm{Y}$, and the balance was Ti. The $\beta$ phase transition temperature of Ti600 alloy is about $1283 \mathrm{~K}\left(1010^{\circ} \mathrm{C}\right)$. Cylindrical specimens with diameter of $8 \mathrm{~mm}$ and height of $15 \mathrm{~mm}$ were prepared. The specimens were hydrogenated at $1023 \mathrm{~K}$ $\left(750^{\circ} \mathrm{C}\right)$ by holding in a pure hydrogen environment for 2 hours followed by air cooling to room temperature. Specimens with various hydrogen contents in the range of 0 to $0.5 \mathrm{wt}$ pct were obtained by controlling the hydrogen pressure, and the actual hydrogen content was determined by weighing the specimen before and after hydrogenation.
Hot compression tests were performed on a Gleeble$1500 \mathrm{D}$ thermo-mechanical test simulator at temperatures of $1033 \mathrm{~K}, 1073 \mathrm{~K}, 1113 \mathrm{~K}$, and $1153 \mathrm{~K}\left(760{ }^{\circ} \mathrm{C}\right.$, $800{ }^{\circ} \mathrm{C}, 840{ }^{\circ} \mathrm{C}$, and $880{ }^{\circ} \mathrm{C}$ ) with strain rates of 0.01 , 0.1 , and $1 \mathrm{~s}^{-1}$. All the hot deformation tests were carried out in air. The formation of an oxidised film on the specimen surface could prevent the escape of hydrogen from the specimen during hot deformation tests. ${ }^{[3,25]}$ In order to minimise the friction and barrel development during deformation, and to prevent bonding of the specimens to the anvils, graphitic lubricant was applied to the mating surfaces. Specimens were first heated to the deformation temperatures at a rate of $10{ }^{\circ} \mathrm{C} / \mathrm{s}$ and held for 3 minutes, and then compressed up to a maximum height reduction of 50 pct (true strain is about 0.7). After deformation, the specimens were immediately quenched in water.

Metallographic specimens were etched with a solution of " 2 pct $\mathrm{HF}+6$ pct $\mathrm{HNO}_{3}+92$ pct $\mathrm{H}_{2} \mathrm{O}$ " (volume fraction) for about 15 seconds and then examined by an OLYMPUS DSX500 optical microscope (OM). Disk samples with a diameter of $3 \mathrm{~mm}$ were used for transmission electron microscope (TEM) investigations. The TEM samples were prepared by electro-polishing in an electrolyte of " $6 \mathrm{vol}$ pct $\mathrm{HCLO}_{4}+34 \mathrm{vol}$ pet $\mathrm{C}_{4} \mathrm{H}_{9} \mathrm{OH}+60$ vol pct $\mathrm{CH}_{3} \mathrm{OH}^{\circ}$ with operating temperatures of $233 \mathrm{~K}$ to $238 \mathrm{~K}\left(-40{ }^{\circ} \mathrm{C}\right.$ to $\left.-35^{\circ} \mathrm{C}\right)$, voltages of 50 to $55 \mathrm{~V}$, and currents of 30 to $35 \mathrm{~mA}$. TEM observations were carried out on a TECNAL G ${ }^{2} 20$ microscope operated at $200 \mathrm{kV}$.

\section{RESULTS AND DISCUSSION}

\section{A. Analysis of Deformation-Induced Temperature Change}

Deformation heating can play an important role in hot compression tests especially at lower deformation temperatures and higher strain rates. To characterise the effect of deformation on the adiabatic heating, the dependences of both the pre-set and actual temperatures on time in a complete hot deformation test of hydrogenfree Ti600 alloy at the lowest deformation temperature of $1033 \mathrm{~K}\left(760^{\circ} \mathrm{C}\right)$ and highest strain rate of $1 \mathrm{~s}^{-1}$ were analysed. The pre-set temperature was pre-programmed, and the actual temperature was determined by thermocouples welded on the tested specimen. The point " 1 " in Figure 1(a) means the time (76 seconds) required for reheating the specimen to $1033 \mathrm{~K}\left(760{ }^{\circ} \mathrm{C}\right)$, and the interval between points " 1 " and " 2 " indicates the holding time (180 seconds). Immediately after point " 2 ," specimen starts to deform. It can be seen from Figure 1(a) that no noticeable variation in temperature is observed before compression deformation takes place. Figure 1(b) presents the change of temperature with the progress of time from 256 to 256.8 seconds. It is clear that there is no significant change in actual temperature before point " 3 " (the time when a strain of 0.61 is reached). After " 3 ," however, a sharp increase in actual temperature is observed. Therefore, deformation does not induce significant change in actual temperature of the tested specimen before strain of 0.61 . The highest actual temperature 


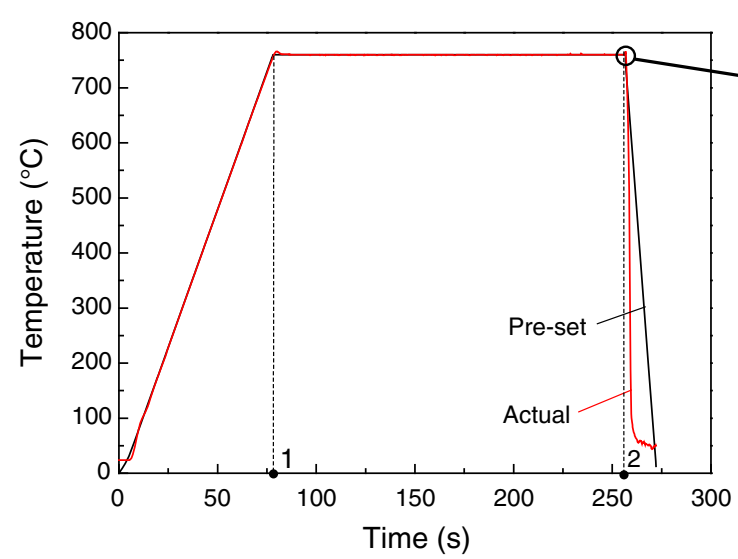

(a)

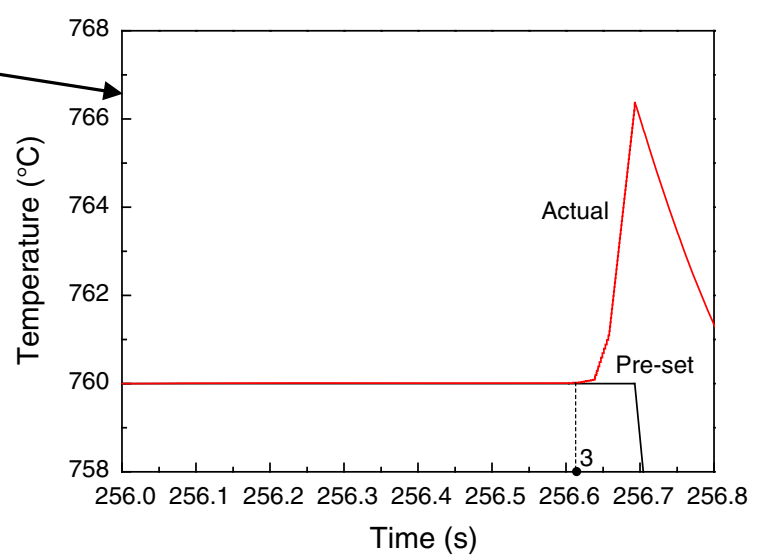

(b)

Fig. 1-Dependences of pre-set and actual temperatures on time of hydrogen-free Ti600 alloy at deformation temperature of $1033 \mathrm{~K}\left(760{ }^{\circ} \mathrm{C}\right)$ and strain rate of $1 \mathrm{~s}^{-1}:(a)$ a complete hot deformation process, and $(b)$ change of temperature with the progress of time.
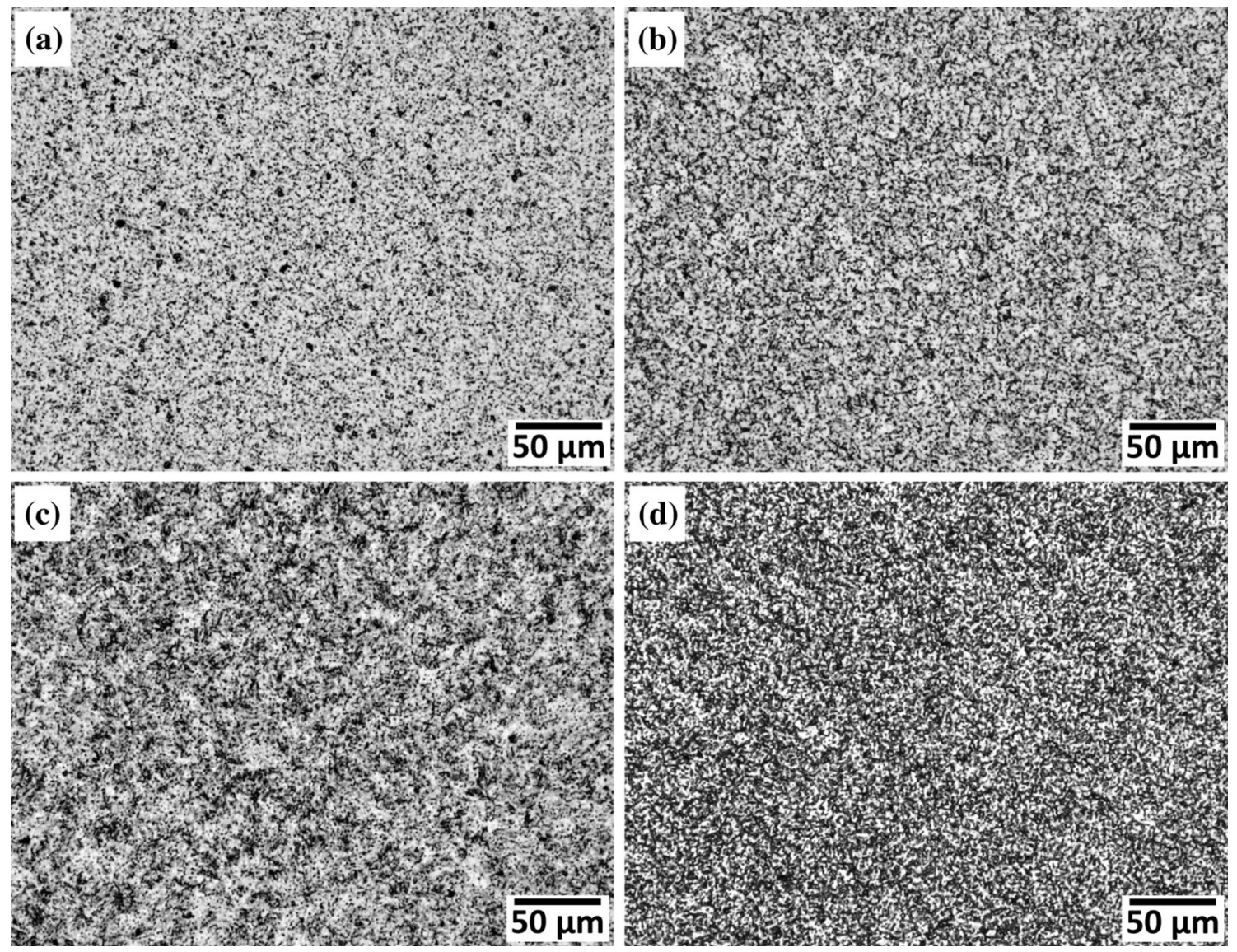

Fig. 2-Microstructures of undeformed Ti600 alloy with different hydrogen contents: $(a) 0 \mathrm{H},(b) 0.1 \mathrm{H},(c) 0.3 \mathrm{H}$, and $(d) 0.5 \mathrm{H}$.

determined at the time of 256.7 seconds (the time when a strain of 0.7 is reached) is $1039.39 \mathrm{~K}\left(766.39^{\circ} \mathrm{C}\right)$, indicating that only $279.39 \mathrm{~K}\left(6.39^{\circ} \mathrm{C}\right)$ is induced by deformation when strain is increased from 0.61 to 0.7 . After 256.7 seconds, both the pre-set and actual temperatures decrease with the beginning of quenching. Based on Figure 1(b), it can be concluded that adiabatic heating effects in compression deformation can be discounted since only a few degrees $\left(\leq 6.39^{\circ} \mathrm{C}\right)$ are induced at higher strain levels $(\geq 0.61)$.

\section{B. Microstructural Characterisation Before Hot Deformation}

Figure 2 presents the microstructures of undeformed Ti600 alloy with different hydrogen contents, in which 

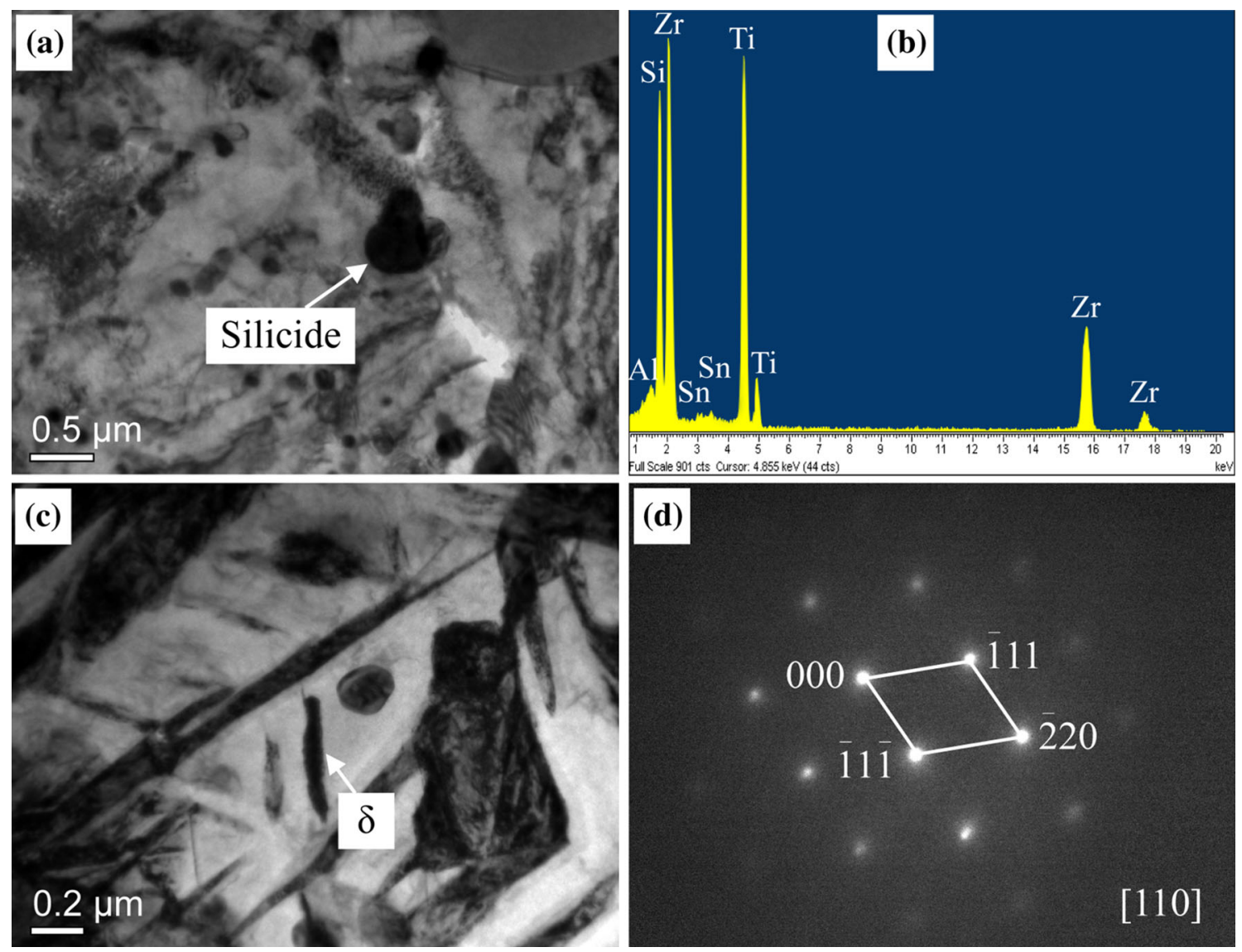

Fig. 3-TEM micrographs of undeformed Ti600 alloy with $(a, b) 0.0$ pct and $(c, d) 0.3$ pct hydrogen: (a) $\beta$ phase, (b) EDS spectrum of silicide, (c) $\delta$ hydride, and (d) SAED pattern of $\delta$.

$0 \mathrm{H}, 0.1 \mathrm{H}, 0.3 \mathrm{H}$, and $0.5 \mathrm{H}$ represent the specimens containing $0,0.1,0.3$, and 0.5 pct hydrogen, respectively. The initial microstructure of the $0 \mathrm{H}$ specimen is mainly composed of $\alpha$ phase (gray color), with a small quantity of $\beta$ phase (dark color) distributed dispersedly in the matrix, as shown in Figure 2(a). After hydrogenation, the volume fraction of $\beta$ phase has increased; the higher the hydrogen content, the greater the volume fraction of $\beta$ phase is observed, as shown in Figures 2(b) through (d). Hydrogenation in near- $\alpha$ and $\alpha$ titanium alloys destabilises the low-temperature hexagonal closepacked $(\mathrm{HCP}) \propto$ phase and stabilises the high-temperature body-centred cubic (BCC) $\beta$ phase. As a result, the $\mathrm{HCP} \alpha$ phase transforms partly into the BCC $\beta$ phase above the eutectoid temperature during hydrogenation process, and the volume fraction of $\beta$ phase is increased as hydrogen is added. ${ }^{[1,6]}$

Figure 3 shows the TEM micrographs of undeformed Ti600 alloy without and with 0.3 pct hydrogen. As shown in Figures 3(a) and (b), silicide exists in the $\beta$ phase of Ti600 alloy without hydrogen addition. This silicide has a hexagonal crystal structure $(a \approx 0.701 \mathrm{~nm}$ and $c \approx 0.368 \mathrm{~nm})$ and is identified as $(\mathrm{TiZr})_{6} \mathrm{Si}_{3}$ with the evidence that the atomic ratio of $(\mathrm{Ti}+\mathrm{Zr})$ to $\mathrm{Si}$ is approximately equal to 2 . Details of the identification of silicides in Ti600 alloy and the evolution of silicides with hydrogen could be found in our previous work. ${ }^{[26]}$ After 0.3 pct hydrogen addition, $\delta$ hydride is found in the matrix, as shown in Figures 3(c) and (d). $\delta$ hydride has a face-centred cubic (FCC) crystal structure with lattice content of $a \approx 0.444 \mathrm{~nm}$. The chemical formula of $\delta$ hydride is $\mathrm{TiH}_{x}$ with $x$ in the range of $1.50-1.94$. The $\delta$ hydride has a $\mathrm{CaF}_{2}$ type structure, in which titanium atoms form the FCC structure and hydrogen atoms that randomly occupy the tetrahedral interstitial sites. ${ }^{[27]}$

\section{Effects of Hydrogen on Flow Behavior}

Figure 4 shows the flow stress curves of the $0 \mathrm{H}, 0.1 \mathrm{H}$, $0.3 \mathrm{H}$, and $0.5 \mathrm{H}$ specimens under different deformation conditions. It can be seen that the flow behavior of the $\mathrm{OH}$ specimen is similar to those of the hydrogenated specimens under the same deformation conditions. The flow stress is sensitively dependent on the temperature and strain rate. As shown in Figure 4, the flow stress decreases with increasing the temperature at a given strain rate. The higher the strain rate, the greater the flow stress is observed. Moreover, all the flow stress curves exhibit a dynamic softening characterisation after a peak stress, indicating that DRX has occurred during the hot deformation. ${ }^{[9,28]}$

Figure 5 shows the influence of hydrogen content on the flow stress of Ti600 alloy deformed at $1073 \mathrm{~K}$ $\left(800{ }^{\circ} \mathrm{C}\right)$ with different strain rates. It is clear that the flow behavior of all the flow stress curves also exhibits a DRX characterisation, i.e., all the curves show an initial 


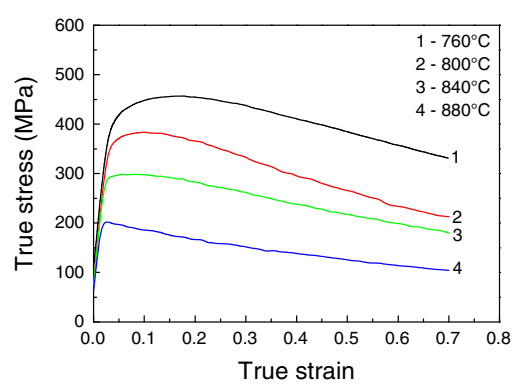

(a)

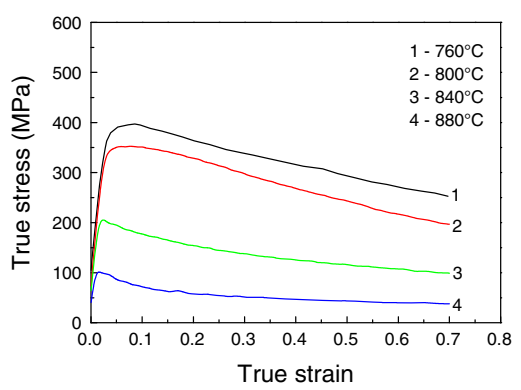

(d)

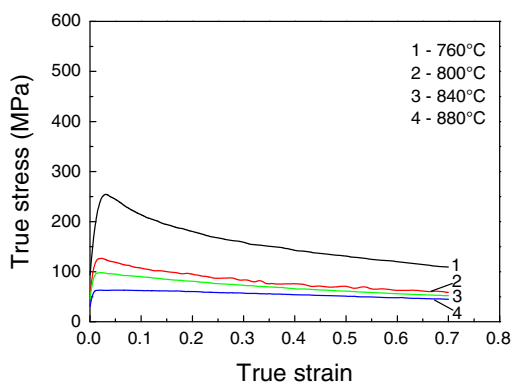

(g)

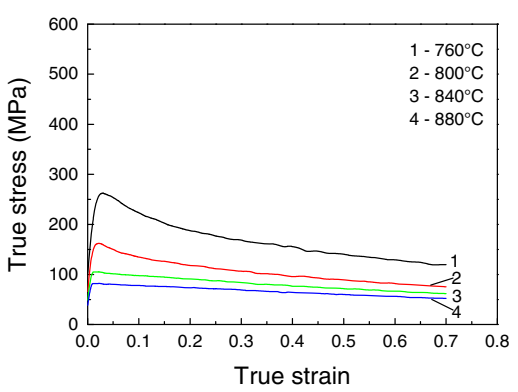

(j)

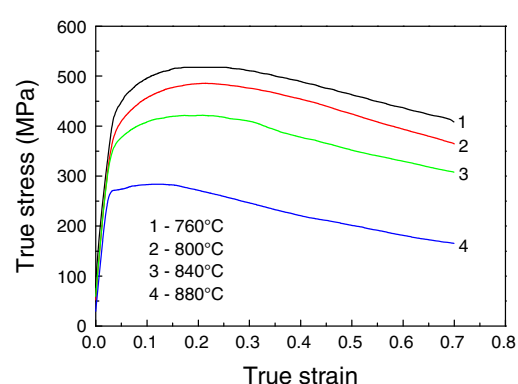

(b)

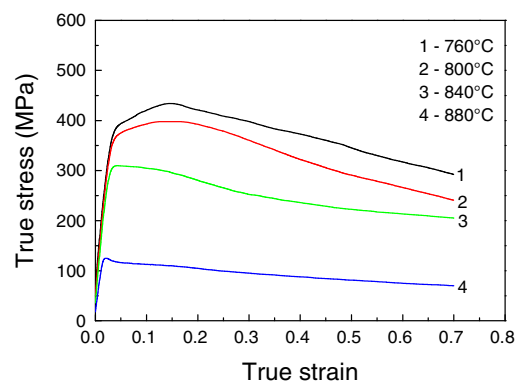

(e)

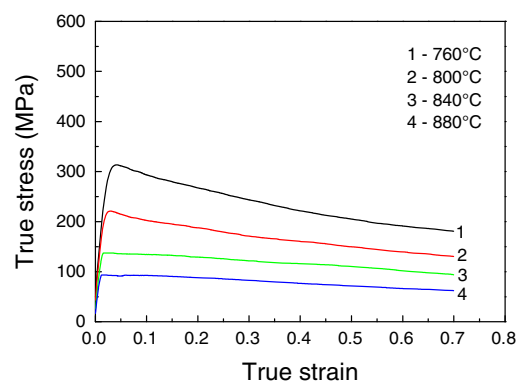

(h)

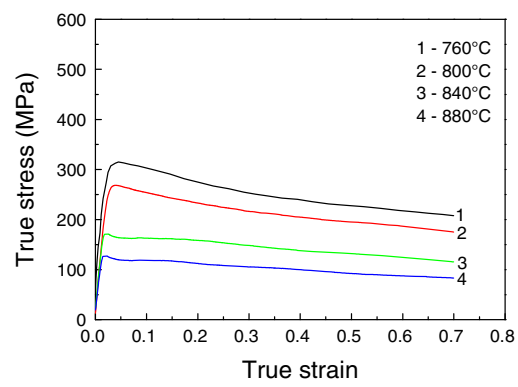

(k)

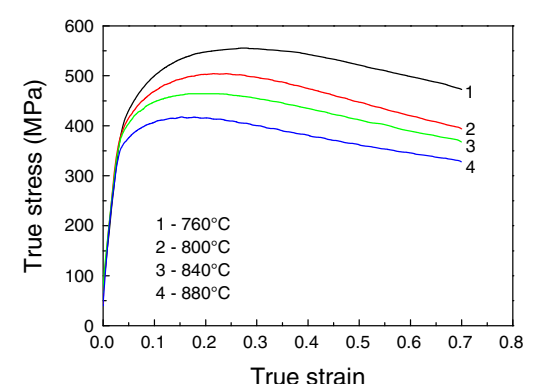

(c)

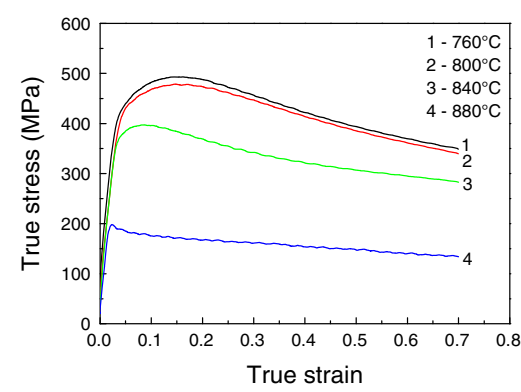

(f)

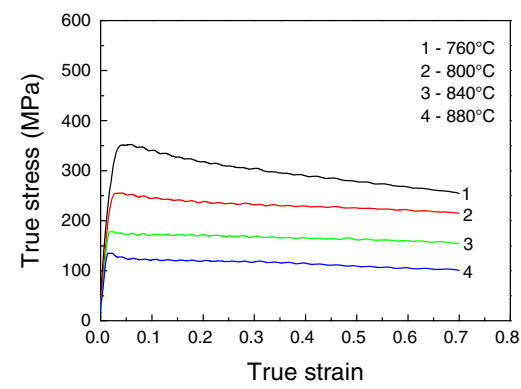

(i)

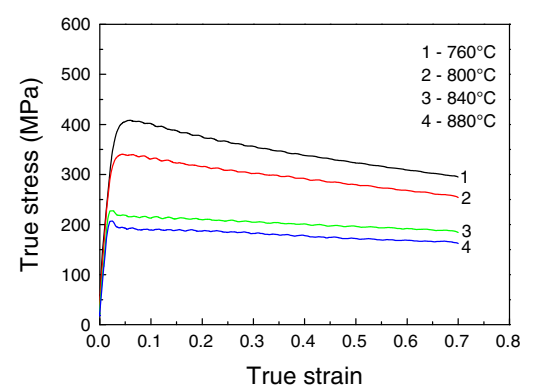

(l)

Fig. 4-Flow stress curves of the ( $a$ through $c) 0 \mathrm{H},(d$ through $f) 0.1 \mathrm{H},(g$ through $i) 0.3 \mathrm{H}$, and $(j$ through $l) 0.5 \mathrm{H}$ specimens under strain rates of $(\mathrm{a}, \mathrm{d}, \mathrm{g}, \mathrm{j}) 0.01 \mathrm{~s}^{-1},(\mathrm{~b}, \mathrm{e}, \mathrm{h}, k) 0.1 \mathrm{~s}^{-1}$, and $(\mathrm{c}, \mathrm{f}, \mathrm{i}, \mathrm{l}) 1 \mathrm{~s}^{-1}$.

increase in the flow stress with strain until a peak stress beyond which a decreased flow stress is observed. In addition, the flow stress decreases gradually with increasing the hydrogen content from 0 to $0.3 \mathrm{pct}$, then increases with the further increase of hydrogen content to 0.5 pct. Therefore, when the hydrogen content is no greater than a certain value, it can favor the decrease of flow stress of Ti600 alloy.

The TEM micrographs of the $0 \mathrm{H}$ and $0.3 \mathrm{H}$ specimens after deformation are illustrated in Figure 6. It can be seen from Figures 6(a) and (b) that DRX grains exist in both the deformed specimens. The corresponding SAED patterns (Figures 6(c) and (d)) of the recrystallized grains suggest HCP crystal structure which proves DRX of $\alpha$ grains. As shown in Figures 6(e) and (f), a large number of dislocations are found in the $0 \mathrm{H}$ specimen relative to that in the $0.3 \mathrm{H}$ specimen, indicating that hydrogen has a positive effect on the enhancement of dislocation mobility during hot deformation, and thus a decreased dislocation density is expected in 


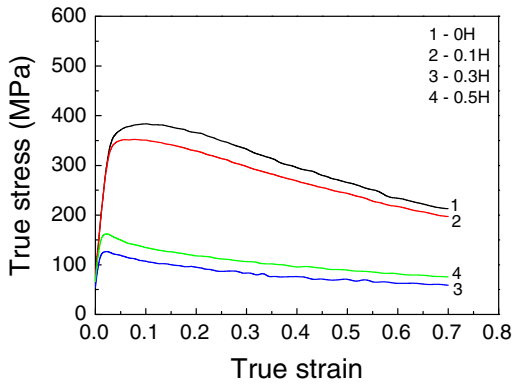

(a)

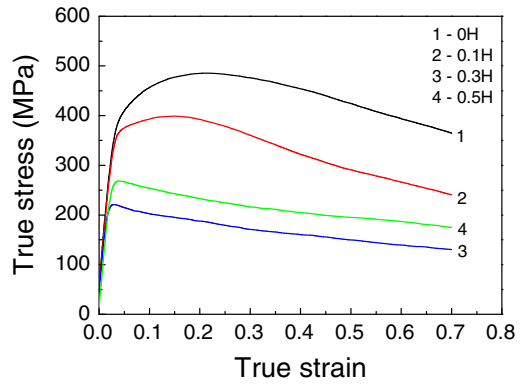

(b)

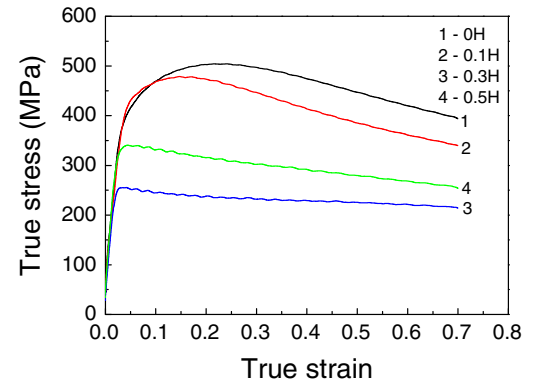

(c)

Fig. 5-Influence of hydrogen content on the flow behavior of Ti600 alloy deformed at $1073 \mathrm{~K}\left(800{ }^{\circ} \mathrm{C}\right)$ with strain rates of $(a) 0.01 \mathrm{~s}^{-1}$, $(b)$ $0.1 \mathrm{~s}^{-1}$, and $(c) 1 \mathrm{~s}^{-1}$.
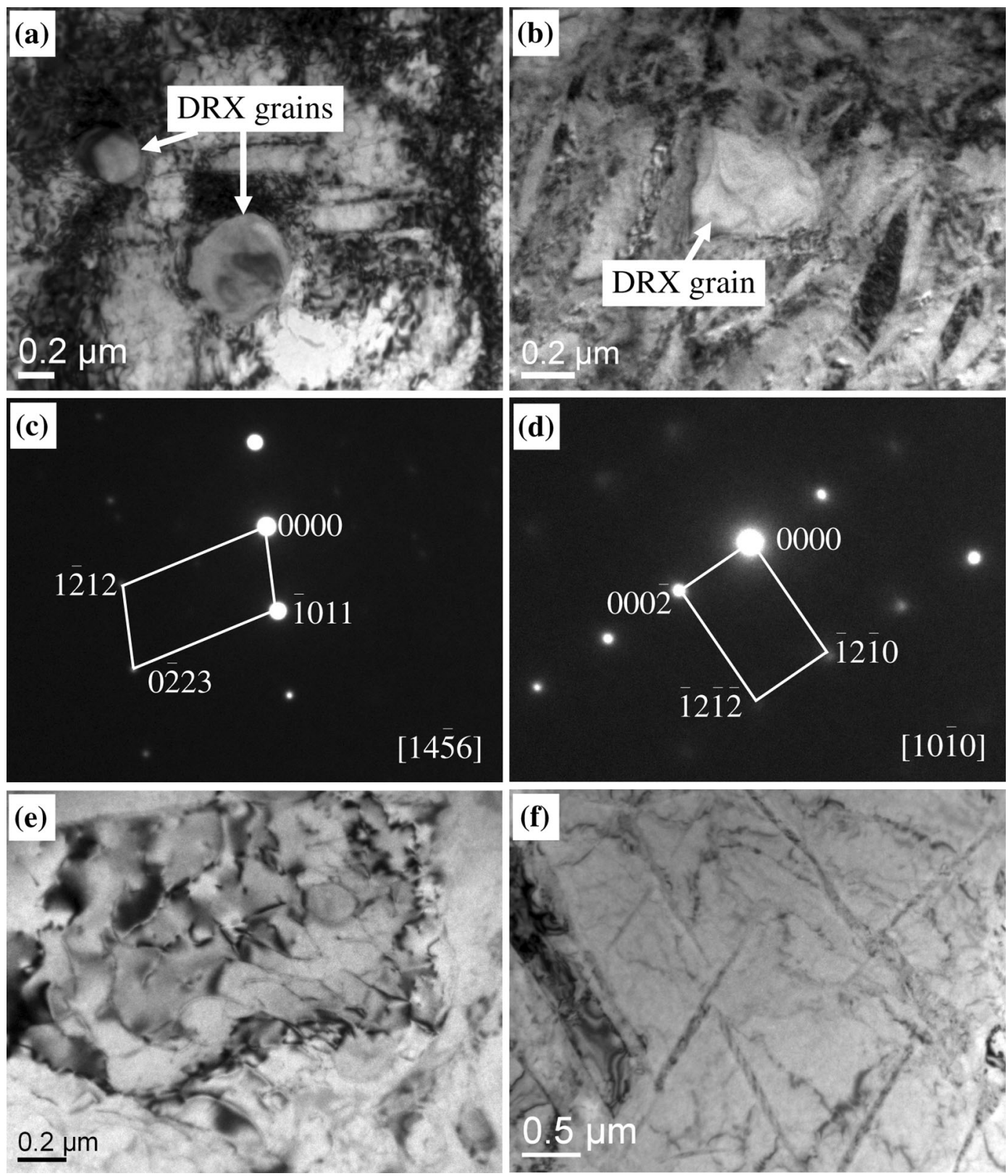

Fig. 6-TEM micrographs of the $(a, c, e) 0 \mathrm{H}$ and $(b, d, f) 0.3 \mathrm{H}$ specimens deformed at $1073 \mathrm{~K}\left(800{ }^{\circ} \mathrm{C}\right)$ with strain rate of $0.1 \mathrm{~s}^{-1}:(\mathrm{a}, \mathrm{b}) \mathrm{DRX}$ grains, (c, d) SAED patterns, and (e, f) dislocations. 
Table I. Values of $\sigma_{\mathrm{p}}$ and $\varepsilon_{\mathrm{p}}$ of all the Tested Specimens at Different Temperatures and Strain Rates

\begin{tabular}{|c|c|c|c|c|c|c|c|}
\hline \multirow[b]{2}{*}{ Specimen } & \multirow{2}{*}{$\begin{array}{c}\text { Temperature } \\
{\left[\mathrm{K}\left({ }^{\circ} \mathrm{C}\right)\right]}\end{array}$} & \multicolumn{2}{|c|}{ Strain Rate $=0.01 \mathrm{~s}^{-1}$} & \multicolumn{2}{|c|}{ Strain Rate $=0.1 \mathrm{~s}^{-1}$} & \multicolumn{2}{|c|}{ Strain Rate $=1 \mathrm{~s}^{-1}$} \\
\hline & & $\sigma_{\mathrm{p}}(\mathrm{MPa})$ & $\varepsilon_{\mathrm{p}}$ & $\sigma_{\mathrm{p}}(\mathrm{MPa})$ & $\varepsilon_{\mathrm{p}}$ & $\sigma_{\mathrm{p}}(\mathrm{MPa})$ & $\varepsilon_{\mathrm{p}}$ \\
\hline \multirow[t]{4}{*}{$0 \mathrm{H}$} & $1033(760)$ & 456.869 & 0.178 & 517.973 & 0.238 & 555.417 & 0.275 \\
\hline & $1073(800)$ & 383.620 & 0.101 & 485.496 & 0.217 & 504.364 & 0.241 \\
\hline & $1113(840)$ & 298.258 & 0.056 & 421.714 & 0.208 & 464.054 & 0.224 \\
\hline & $1153(880)$ & 201.763 & 0.027 & 283.846 & 0.115 & 417.559 & 0.153 \\
\hline \multirow[t]{4}{*}{$0.1 \mathrm{H}$} & $1033(760)$ & 397.112 & 0.086 & 434.115 & 0.148 & 493.012 & 0.161 \\
\hline & $1073(800)$ & 352.410 & 0.077 & 397.726 & 0.125 & 478.817 & 0.147 \\
\hline & $1113(840)$ & 205.159 & 0.024 & 309.849 & 0.044 & 397.279 & 0.086 \\
\hline & $1153(880)$ & 101.998 & 0.022 & 124.776 & 0.023 & 198.054 & 0.023 \\
\hline \multirow[t]{4}{*}{$0.3 \mathrm{H}$} & $1033(760)$ & 253.757 & 0.029 & 313.360 & 0.040 & 351.302 & 0.041 \\
\hline & $1073(800)$ & 126.632 & 0.023 & 221.063 & 0.030 & 255.242 & 0.033 \\
\hline & $1113(840)$ & 98.088 & 0.022 & 137.596 & 0.026 & 177.829 & 0.026 \\
\hline & $1153(880)$ & 63.102 & 0.021 & 93.478 & 0.022 & 134.983 & 0.022 \\
\hline \multirow[t]{4}{*}{$0.5 \mathrm{H}$} & $1033(760)$ & 262.359 & 0.029 & 314.740 & 0.045 & 408.299 & 0.059 \\
\hline & $1073(800)$ & 162.122 & 0.023 & 268.558 & 0.039 & 340.763 & 0.044 \\
\hline & $1113(840)$ & 105.498 & 0.022 & 170.917 & 0.026 & 227.349 & 0.027 \\
\hline & $1153(880)$ & 82.344 & 0.021 & 127.260 & 0.023 & 207.127 & 0.025 \\
\hline
\end{tabular}

the deformed matrix. The mechanism of hydrogeninduced decreasing of flow stress and the effect of hydrogen on the microstructural evolution of Ti600 alloy are detailed in our previous studies. ${ }^{[6,29]}$

Table I presents the values of $\sigma_{\mathrm{p}}$ (peak stress) and $\varepsilon_{\mathrm{p}}$ (strain to peak stress) of all the tested specimens at different temperatures and strain rates. It can be seen that both $\sigma_{\mathrm{p}}$ and $\varepsilon_{\mathrm{p}}$ decrease with the increase of temperature under a given strain rate, and increase with the increase of strain rate under a given temperature. The value of $\varepsilon_{\mathrm{p}}$ shows an increasing trend with $\sigma_{\mathrm{p}}$ under a given temperature or strain rate. In addition, hydrogenation in Ti600 alloy induces decreased $\sigma_{\mathrm{p}}$ and $\varepsilon_{\mathrm{p}}$. As indicated in Table I, both $\sigma_{\mathrm{p}}$ and $\varepsilon_{\mathrm{p}}$ decrease gradually with hydrogen until minimum values are obtained at the hydrogen content of 0.3 pct. Further increasing hydrogen content from 0.3 to 0.5 pct leads to a slight increase in both values. Therefore, hydrogen affects not only the peak stress but also the value of strain to peak stress of Ti600 alloy during hot deformation.

\section{Effects of Hydrogen on Critical Stress and Strain for $D R X$}

Typically, stress-strain curves such as that of Figure 7 can be obtained when DRX occurs at high temperature. In Figure 7, $\sigma_{\mathrm{c}}$ is the critical stress for the initiation of $\mathrm{DRX}, \varepsilon_{\mathrm{c}}$ is the strain to $\sigma_{\mathrm{c}}$, and $\sigma_{\mathrm{s}}$ is the steady state stress. DRX is initiated at elevated temperature at some critical stress $\sigma_{\mathrm{c}}$ attained at a critical strain $\varepsilon_{\mathrm{c}}$. As a softening phenomenon, DRX leads to a decrease with the increase of strain until a steady state stress $\sigma_{\mathrm{s}}$ is obtained. The stress, however, does not decrease immediately after $\sigma_{\mathrm{c}}$ has been attained. The stress continuously increases beyond $\sigma_{\mathrm{c}}$ until the softening due to the progress of DRX balances the continuing strain hardening of metals during hot deformation (Figure 7).

Poliak and Jonas ${ }^{[15]}$ developed a model based on the principles of irreversible thermodynamics for determining

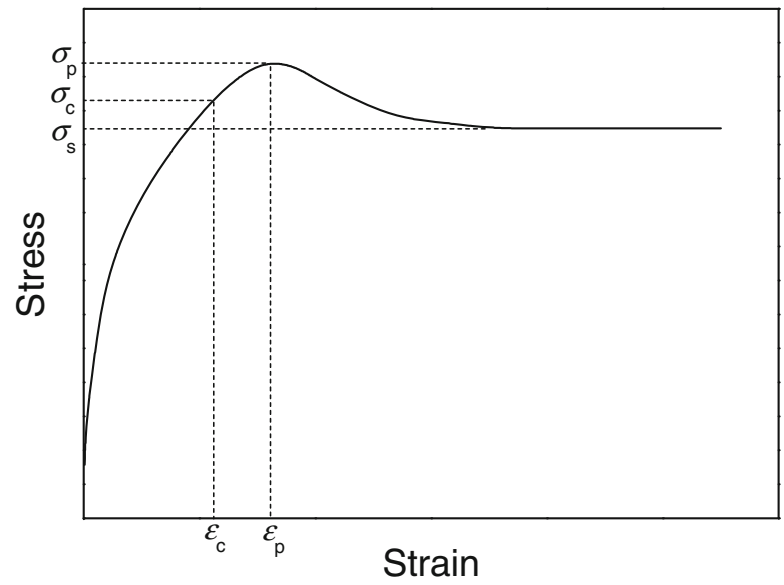

Fig. 7-Typical stress-strain curve with DRX occurs.

the initiation of DRX. They found that the initiation of DRX corresponds to an inflection in the $\theta$ vs $\sigma$ curve, and the minimum value of $-(\partial \theta / \partial \sigma)$ vs $\sigma$ curve could be regarded as characterising the instant when DRX was initiated. Here, $\theta$ is the conventional strain-hardening rate and is defined as $\theta=(\partial \sigma / \partial \varepsilon)_{\dot{\varepsilon}}$, and $\sigma$ and $\varepsilon$ are the flow stress and strain, respectively. In the current work, each flow stress curve was fitted and smoothed with a seventh-order polynomial using the MATLAB R2012b software before the calculations. The smoothing helped eliminate the signal noise and fluctuations present in the experimental curves, and, therefore, permit the differentiation analysis being operated effectively.

The $-(\partial \theta / \partial \sigma)$ vs $\sigma$ curves of the $0 \mathrm{H}$ specimens with different strain rates and temperatures are illustrated in Figures 8(a) and (b), respectively. In the figure, the minimum points of the $-(\partial \theta / \partial \sigma)$ curves are the critical stresses, and the critical strains that correspond to these critical stresses can be determined from the flow curves. Under a given temperature, the critical stress shifts to a 


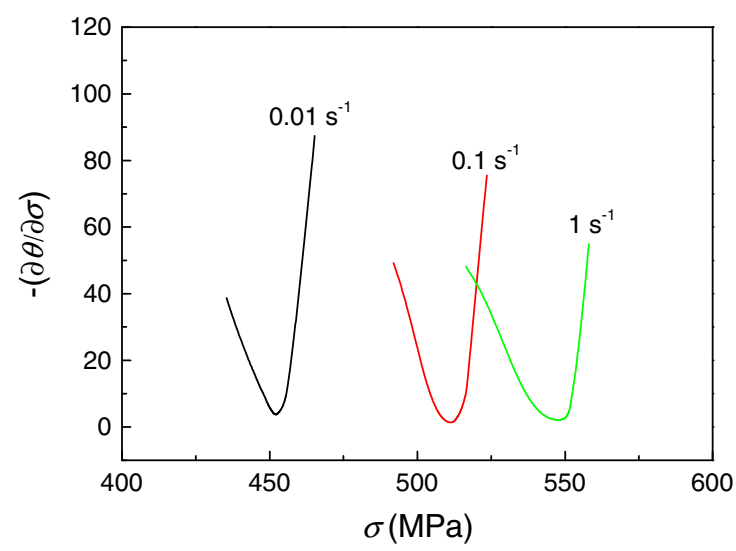

(a)

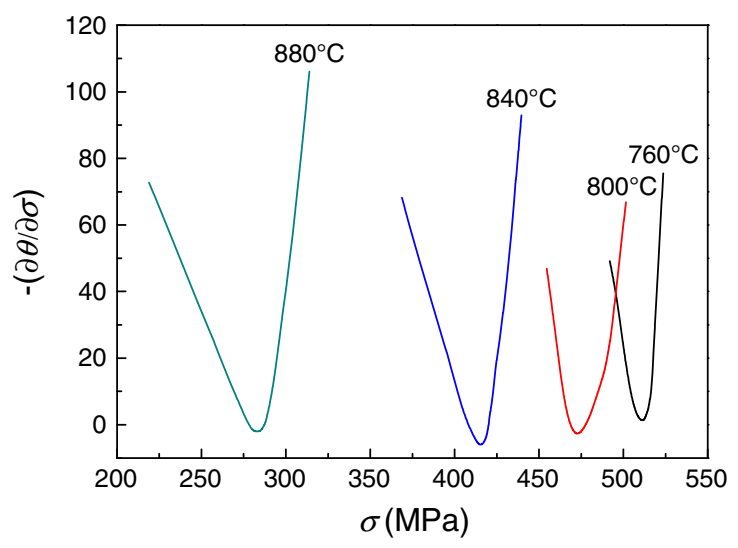

(b)

Fig. 8- $-(\partial \theta / \partial \sigma) v s \sigma$ curves of the $0 \mathrm{H}$ specimens with $(a)$ temperature of $1033 \mathrm{~K}\left(760{ }^{\circ} \mathrm{C}\right)$ and $(b)$ strain rate of $0.1 \mathrm{~s}^{-1}$.

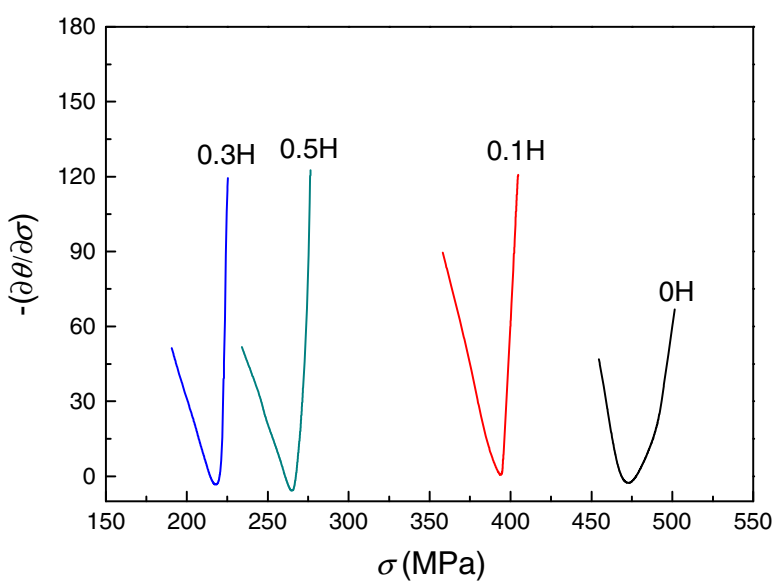

Fig. 9-Effects of hydrogen on the flow stress dependence of $-(\partial \theta / \partial \sigma)$ at $1073 \mathrm{~K}\left(800^{\circ} \mathrm{C}\right)$ with strain rate of $0.1 \mathrm{~s}^{-1}$.

higher value as strain rate is increased, as shown in Figure 8(a). Figure 8(b) indicates that temperature has a negative effect on the value of critical stress: the higher the temperature, the lower the critical stress is obtained.

Figure 9 shows the effects of hydrogen on the critical stress of Ti600 alloy during hot deformation. It can be seen that the critical stress decreases gradually with the increase of hydrogen in the hydrogen range of 0 to 0.3 pct. When the hydrogen content is greater than 0.3 pct, however, hydrogen shows a positive effect on the increase of the critical stress. The strains to the critical stresses of the $0 \mathrm{H}, 0.1 \mathrm{H}, 0.3 \mathrm{H}$, and $0.5 \mathrm{H}$ specimens are obtained as $0.135,0.104,0.024$, and 0.032 , respectively, from the relevant flow curves. The addition of proper hydrogen (no greater than $0.3 \mathrm{pct}$ ) benefits the decrease of the critical strain for the initiation of DRX.

DRX in titanium alloys occurs when a critical strain is met. ${ }^{[2,30,31]}$ This critical strain corresponds to a critical dislocation density $\rho_{c}$ as the strain proceeds during hot deformation process. ${ }^{[32]}$ Once the dislocation density of a grain reaches a critical value, DRX takes place. The value of $\rho_{\mathrm{c}}$ depends on deformation conditions and can be determined from the energy changes in relation to the formation of a nucleus on a pre-existing grain boundary as ${ }^{[33]}$

$$
\rho_{\mathrm{c}}=\left(\frac{20 \gamma_{i} \dot{\varepsilon}}{3 \mathbf{b} l M \tau^{2}}\right)^{1 / 3}
$$

where $\gamma_{i}$ is the grain boundary energy, $\dot{\varepsilon}$ is the macroscopic strain rate of grains aggregate, $\mathbf{b}$ is the Burger's vector, $l$ is the dislocation mean free path, $M$ is the grain boundary mobility, and $\tau$ is the dislocation line energy.

Previous studies have indicated that the addition of some hydrogen in titanium alloys decreases the grain boundary energy ${ }^{[34]}$ and increases the grain boundary sliding ability, ${ }^{[1,6]}$ indicating that a decreased $\rho_{\mathrm{c}}$ will be obtained after hydrogen addition based on Eq. [1], and a decreased critical strain that corresponds to the critical dislocation density for the initiation of DRX is, therefore, obtained after hydrogen addition. The volume fraction of $\beta$ phase increases gradually with increasing the hydrogen content. Since the solubility of hydrogen in $\beta$ phase is far more than that in $\alpha$ phase, large numbers of hydrogen atoms will enter the interstitial sites and function as a solution strengthening. As a result, the diffusion of interstitial atoms will be retarded, and the grain boundary mobility will be reduced at relatively high hydrogen content $(0.5 \mathrm{pct}$ in this work). ${ }^{[35]}$ A slightly increased critical strain for the initiation of $\mathrm{DRX}$ of the $0.5 \mathrm{H}$ specimen relative to that of the $0.3 \mathrm{H}$ specimen is, therefore, expected due to the increase of $\rho_{\mathrm{c}}$.

Figures 10(a) through (d) show the relationships between $\sigma_{\mathrm{c}}$ and $\sigma_{\mathrm{p}}$ of the $0 \mathrm{H}, 0.1 \mathrm{H}, 0.3 \mathrm{H}$, and $0.5 \mathrm{H}$ specimens, respectively. As can be seen from Figure 10, $\sigma_{\mathrm{c}}$ depends linearly on $\sigma_{\mathrm{p}}$ for all the specimens that with and without hydrogen additions. The relationship between $\sigma_{\mathrm{c}}$ and $\sigma_{\mathrm{p}}$ of the $0 \mathrm{H}, 0.1 \mathrm{H}, 0.3 \mathrm{H}$, and $0.5 \mathrm{H}$ specimens can be expressed, respectively, as $\sigma_{\mathrm{c}} / \sigma_{\mathrm{p}}=0.977,0.988,0.998$, and 0.995 after linear regressions.

Figure 11 presents the dependence of $\varepsilon_{\mathrm{c}}$ for the initiation of DRX on $\varepsilon_{\mathrm{p}}$. As shown in Figure 11(a), the linear relationship between $\varepsilon_{\mathrm{c}}$ and $\varepsilon_{\mathrm{p}}$ of the $0 \mathrm{H}$ specimen can be acquired as $\varepsilon_{\mathrm{c}} / \varepsilon_{\mathrm{p}}=0.599$, which agrees well with other results $\left(\varepsilon_{\mathrm{c}} / \varepsilon_{\mathrm{p}}=0.37\right.$ to 0.65$)$ for near- $\alpha$ high-temperature titanium alloys. ${ }^{[22,30]}$ Similarly, the 


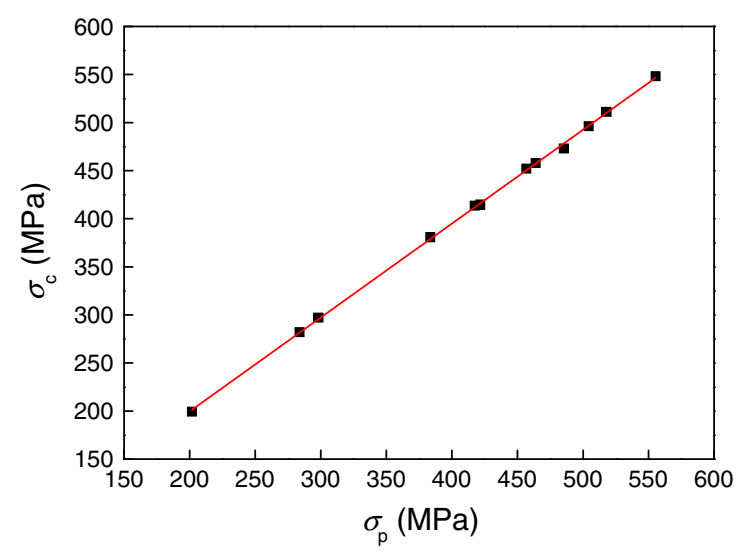

(a)

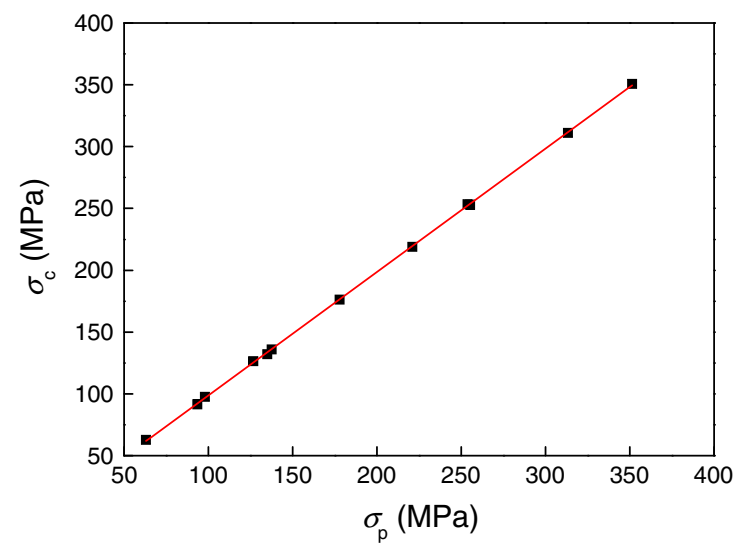

(c)

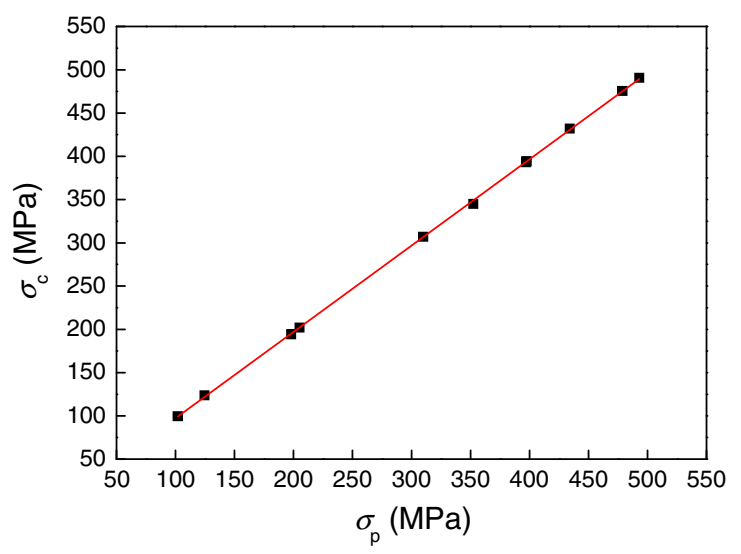

(b)

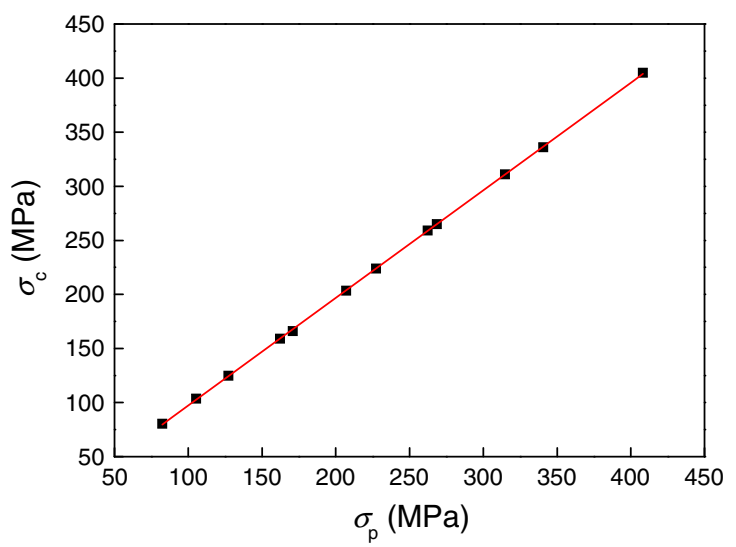

(d)

Fig. 10 - Dependence of the critical stress for the initiation of DRX on peak stress of the $(a) 0 \mathrm{H},(b) 0.1 \mathrm{H},(c) 0.3 \mathrm{H}$, and $(d) 0.5 \mathrm{H}$ specimens.

obtained values of $\varepsilon_{\mathrm{c}} / \varepsilon_{\mathrm{p}}$ for the $0.1 \mathrm{H}, 0.3 \mathrm{H}$, and $0.5 \mathrm{H}$ specimens are $0.809,0.975$, and 0.880 , respectively, as shown in Figures 11(b) through (d). It is clear that the ratio of $\varepsilon_{\mathrm{c}}$ to $\varepsilon_{\mathrm{p}}$ shows an increasing trend with hydrogen when the hydrogen content is no greater than $0.3 \mathrm{pct}$, beyond which a decreased $\varepsilon_{\mathrm{c}} / \varepsilon_{\mathrm{p}}$ is caused. The distance from $\varepsilon_{\mathrm{c}}$ to $\varepsilon_{\mathrm{p}}$ has been narrowed after proper hydrogen addition (no greater than $0.3 \mathrm{pct}$ ). This result indicates that hydrogen helps shorten the time required for balancing the softening due to the progress of DRX and the continuing strain hardening during hot deformation of Ti600 alloy.

\section{E. Effects of Hydrogen on DRX Kinetics}

DRX is one of the most important softening mechanisms in deformed metals at elevated temperatures. In general, DRX progresses in a sigmoidal manner with respect to time. For a constant strain rate, time can be replaced by strain, and the volume fraction of DRX $\left(X_{\mathrm{d}}\right)$ can be described by an Avrami-type equation as ${ }^{[36]}$

$$
X_{\mathrm{d}}=1-\exp \left[-k\left(\frac{\varepsilon-\varepsilon_{\mathrm{c}}}{\varepsilon_{\mathrm{p}}}\right)^{n}\right]
$$

where $k$ and $n$ are DRX parameters depending on chemical compositions and hot deformation conditions.
In order to determine the values of $k$ and $n$, Eq. [2] can be rewritten as follows after taking double natural logarithms on its both sides

$$
\ln \left[\ln \left(\frac{1}{1-X_{\mathrm{d}}}\right)\right]=\ln k+n \ln \left(\frac{\varepsilon-\varepsilon_{\mathrm{c}}}{\varepsilon_{\mathrm{p}}}\right)
$$

The value of $\varepsilon_{\mathrm{p}}$ in Eq. [3] can be determined directly from a flow curve, and $\varepsilon_{\mathrm{c}}$ can be obtained using the aforementioned method proposed by Poliak and Jonas. ${ }^{[15]}$ The value of $X_{\mathrm{d}}$ under different deformation conditions, however, is hard to be measured by extensive quantitative microstructural analysis. To determine the volume fraction of DRX, the following expression is employed in the current work ${ }^{[37]}$ :

$$
X_{\mathrm{d}}=\frac{\sigma_{\mathrm{p}}-\sigma}{\sigma_{\mathrm{p}}-\sigma_{\mathrm{s}}}
$$

Based on Eq. [4], the volume fraction of dynamic recrystallized grains can be determined, and the values of $k$ and $n$ can be obtained by combining Eqs. [3] and [4] through further analysis of the true stress $v s$ true strain curves under different deformation conditions. In some cases such as low deformation temperature and high strain rate, incomplete DRX may occur, and it is hard to acquire a steady stress directly from the flow stress curve 


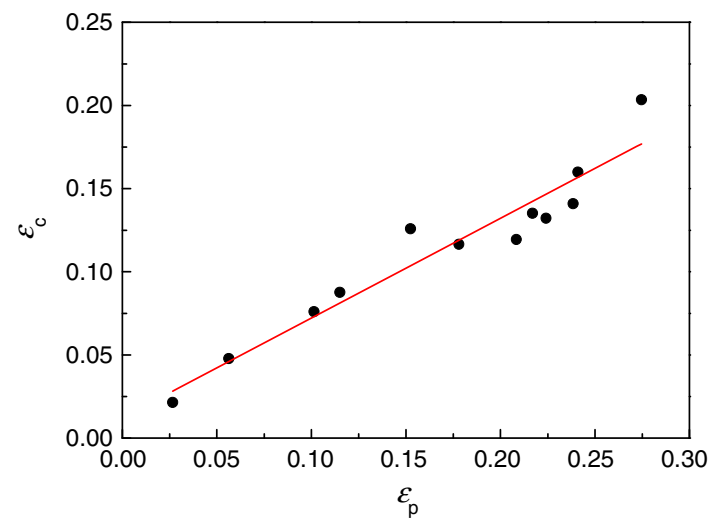

(a)

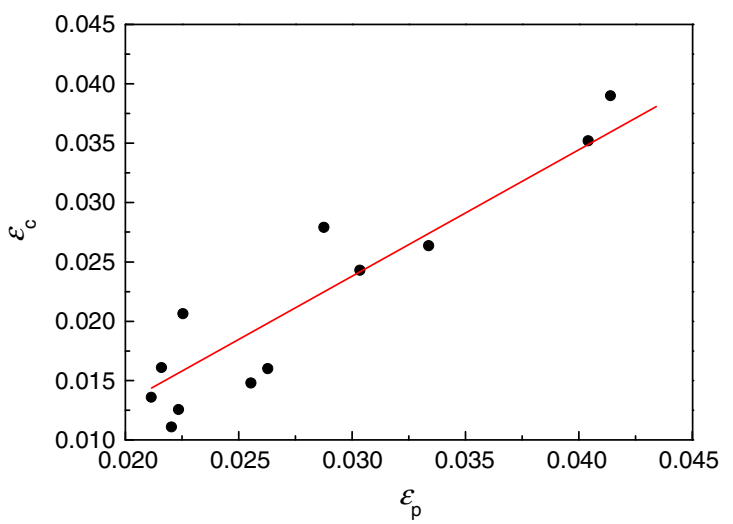

(c)

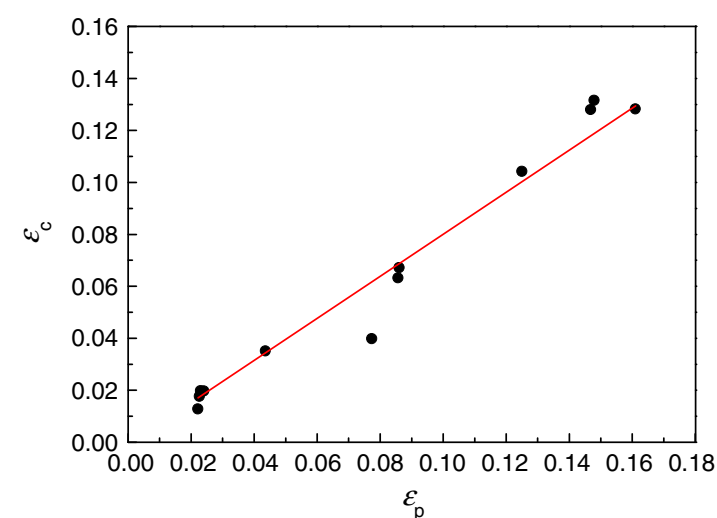

(b)

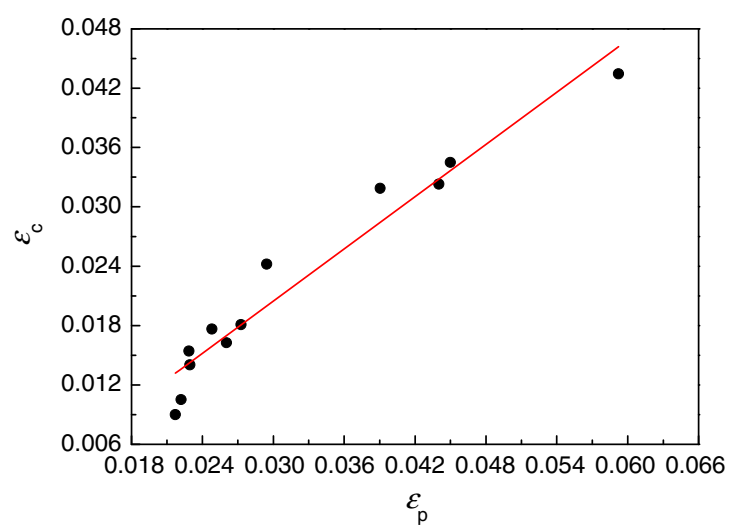

(d)

Fig. 11-Dependence of the critical strain for the initiation of DRX on strain to peak stress of the $(a) 0 \mathrm{H},(b) 0.1 \mathrm{H},(c) 0.3 \mathrm{H}$, and $(d) 0.5 \mathrm{H}$ specimens.

since the stress beyond $\sigma_{\mathrm{p}}$ decreases gradually with strain throughout the whole deformation process. In the current work, the stress obtained at the maximum strain of 0.7 is regarded as the steady stress $\sigma_{\mathrm{s}}$.

Figure 12 shows the relationship between $\ln \left[\ln \left(1 /\left(1-X_{\mathrm{d}}\right)\right)\right]$ and $\ln \left[\left(\varepsilon-\varepsilon_{\mathrm{c}}\right) / \varepsilon_{\mathrm{p}}\right]$ under different deformation conditions. It can be seen that $\ln \left[\ln \left(1 /\left(1-X_{\mathrm{d}}\right)\right)\right]$ depends linearly on $\ln \left[\left(\varepsilon-\varepsilon_{\mathrm{c}}\right) / \varepsilon_{\mathrm{p}}\right]$ for all the tested specimens. The values of $\ln k$ and $n$ can, therefore, be determined, respectively, from the intercept and slope of a regressed line. The calculated values of $k$ and $n$ of the tested specimens after linear analysis are presented in Table II. It can be seen that the value of $k$ decreases gradually with increasing the hydrogen content. Differently, $n$ decreases gradually with hydrogen at first, then to a minimum value at the hydrogen content of 0.3 pct, and finally it increases when the hydrogen content is greater than 0.3 pct. In Table II, the correlation coefficient $R$ is a statistical measure of how well the regression line approximates the real data points. $R$ is most often seen as a number between 0 and 1 . An $R$ near 1 indicates that a regression line fits the data well, while an $R$ close to 0 indicates that a regression line does not fit the data very well.

Based on Eq. [2] and Table II, the kinetics models of DRX for Ti600 alloys with $0,0.1,0.3$, and 0.5 pct hydrogen contents can be well established as

$$
\begin{aligned}
& X_{\mathrm{d}}=1-\exp \left[-0.211\left(\frac{\varepsilon-\varepsilon_{\mathrm{c}}}{\varepsilon_{\mathrm{p}}}\right)^{2.844}\right]\langle 0 \mathrm{H}\rangle \\
& X_{\mathrm{d}}=1-\exp \left[-0.159\left(\frac{\varepsilon-\varepsilon_{\mathrm{c}}}{\varepsilon_{\mathrm{p}}}\right)^{2.033}\right]\langle 0.1 \mathrm{H}\rangle \\
& X_{\mathrm{d}}=1-\exp \left[-0.098\left(\frac{\varepsilon-\varepsilon_{\mathrm{c}}}{\varepsilon_{\mathrm{p}}}\right)^{0.991}\right]\langle 0.3 \mathrm{H}\rangle \\
& X_{\mathrm{d}}=1-\exp \left[-0.080\left(\frac{\varepsilon-\varepsilon_{\mathrm{c}}}{\varepsilon_{\mathrm{p}}}\right)^{1.197}\right]\langle 0.5 \mathrm{H}\rangle .
\end{aligned}
$$

Figure 13 shows the calculated results based on the kinetics model of DRX for Ti600 alloy without hydrogen. The volume fractions of DRX as functions of strain at different deformation temperatures and strain rates are shown in Figures 13(a) and (b), respectively. As shown in Figure 13(a), the volume fraction of DRX reaches a constant value of 1 as the strain increases, and the strain required for the same amount of recrystallized fraction increases with decreasing the deformation 


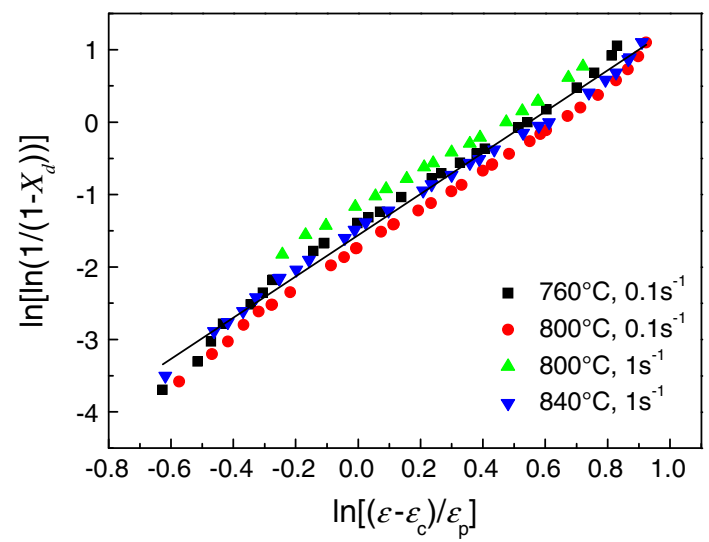

(a)

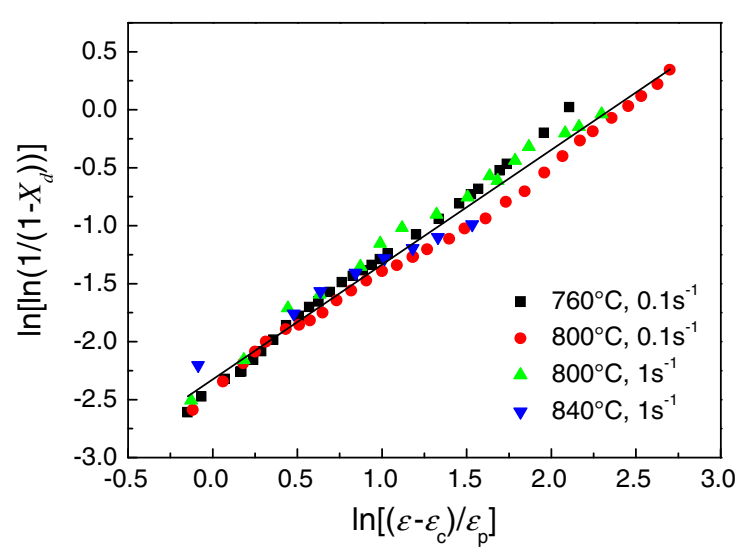

(c)

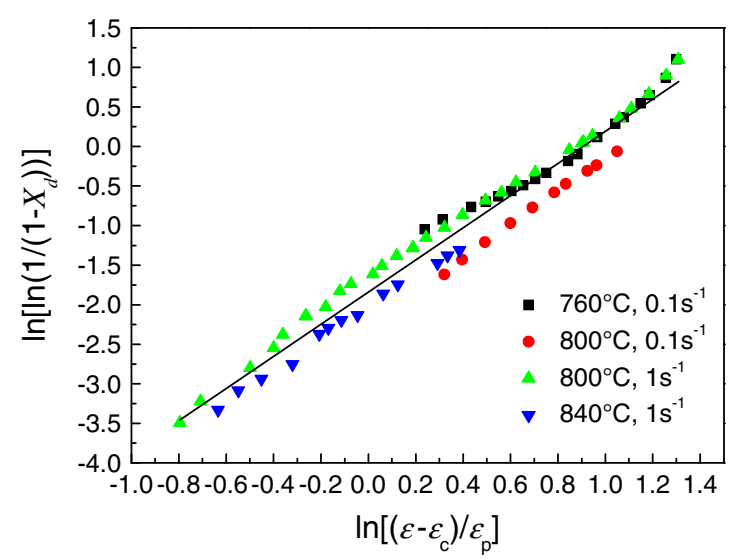

(b)

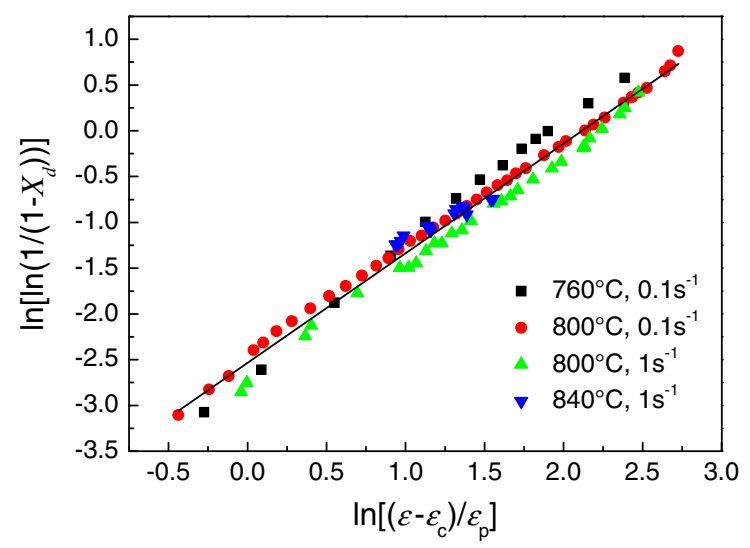

(d)

Fig. 12-Relationship between $\ln \left[\ln \left(1 /\left(1-X_{\mathrm{d}}\right)\right)\right]$ and $\ln \left[\left(\varepsilon-\varepsilon_{\mathrm{c}}\right) / \varepsilon_{\mathrm{p}}\right]$ of the $(a) 0 \mathrm{H},(b) 0.1 \mathrm{H},(c) 0.3 \mathrm{H}$, and $(d) 0.5 \mathrm{H}$ specimens under different deformation conditions.

Table II. Calculated Values of $\boldsymbol{k}$ and $\boldsymbol{n}$ for the Tested Specimens

\begin{tabular}{lccc}
\hline Specimen & $k$ & $n$ & $R$ \\
\hline $0 \mathrm{H}$ & 0.211 & 2.844 & 0.972 \\
$0.1 \mathrm{H}$ & 0.159 & 2.033 & 0.969 \\
$0.3 \mathrm{H}$ & 0.098 & 0.991 & 0.979 \\
$0.5 \mathrm{H}$ & 0.080 & 1.197 & 0.979 \\
\hline
\end{tabular}

temperature. Figure 13(b) indicates that strain rate has a positive effect on the strain required for the same amount of recrystallized fraction. At the strain rate of $0.01 \mathrm{~s}^{-1}$, the volume fraction of DRX reaches 1 as the strain increases up to 0.4 . At the strain rates of 0.1 and $1 \mathrm{~s}^{-1}$, however, the highest volume fractions of DRX are observed, respectively, as 0.959 and 0.876 at the maximum strain of 0.7 , indicating that incomplete DRX has occurred during the whole deformation process that performed at $1073 \mathrm{~K}\left(800{ }^{\circ} \mathrm{C}\right)$, when the strain rate is greater than $0.01 \mathrm{~s}^{-1}$, as shown in Figure 13(b).

Figure 14 shows the OM and TEM structures of the $0 \mathrm{H}$ specimen deformed at $1073 \mathrm{~K}\left(800{ }^{\circ} \mathrm{C}\right)$ with a strain rate of $0.01 \mathrm{~s}^{-1}$. It can be seen from Figure 14(a) that the equiaxed $\alpha$ grains exhibit a character of full dynamic globularisation as compared to that without deformation (Figure 2(a)), indicating that DRX has completed because dynamic globularisation is a type of DRX. ${ }^{[38]}$ McQueen et al. ${ }^{[39]}$ found that DRX mainly occurred in the $\alpha$ phase because it has lower stacking fault energy due to its HCP crystal structure. Figure 14(b) presents a more detailed observation of DRX grains, indicating that complete DRX has been obtained after hot deformation at $1073 \mathrm{~K}\left(800{ }^{\circ} \mathrm{C}\right)$ with a strain rate of $0.01 \mathrm{~s}^{-1}$. By comparing Figure 14(b) with Figure 6(a), it is clear that the fraction of DRX grains has decreased with increasing strain rate from 0.01 to $0.1 \mathrm{~s}^{-1}$, which is consistent with the result shown in Figure 13(b). When the strain rate is increased from 0.01 to $0.1 \mathrm{~s}^{-1}$, the time for deformation is reduced from 70 to 7 second. Since an incubation period is required for the nucleation of dynamic recrystallized grains, such significant reduction in deformation time will induce parts of DRX grains non-nucleated.

Figure 15 illustrates the effects of hydrogen on the volume fraction of DRX at $1153 \mathrm{~K}\left(880^{\circ} \mathrm{C}\right)$ with strain rate of $0.01 \mathrm{~s}^{-1}$ based on the developed kinetics models. It is clear that the strain range from the initiation to the completion of DRX increases gradually with hydrogen in the hydrogen range of 0 to $0.3 \mathrm{pct}$, and a slightly 


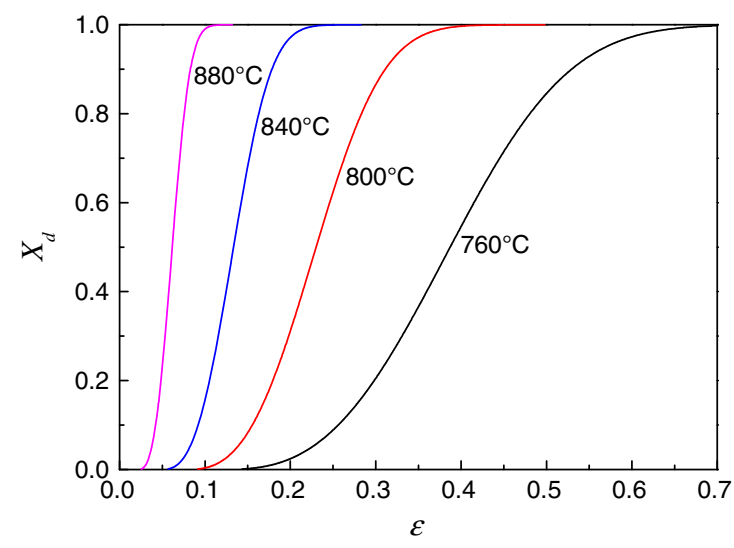

(a)

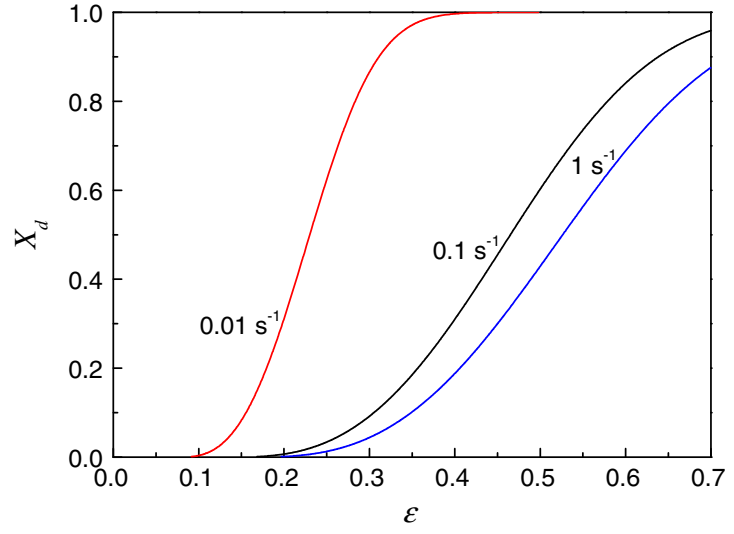

(b)

Fig. 13 - Calculated volume fraction of DRX for Ti600 alloy without hydrogen obtained under $(a)$ strain rate of $0.01 \mathrm{~s}^{-1}$ and $(b)$ temperature of $1073 \mathrm{~K}\left(800^{\circ} \mathrm{C}\right)$.
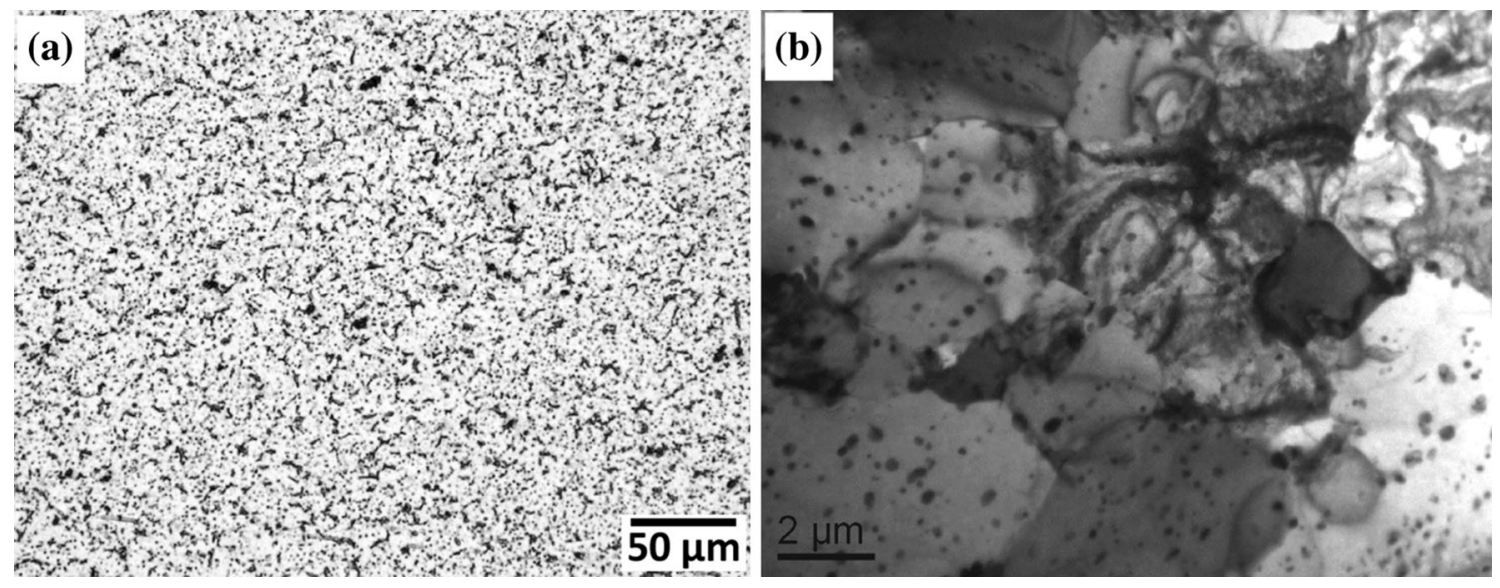

Fig. $14-(a) \mathrm{OM}$ and (b) TEM structures of the $0 \mathrm{H}$ specimen deformed at $1073 \mathrm{~K}\left(800^{\circ} \mathrm{C}\right)$ with strain rate of $0.01 \mathrm{~s}^{-1}$.

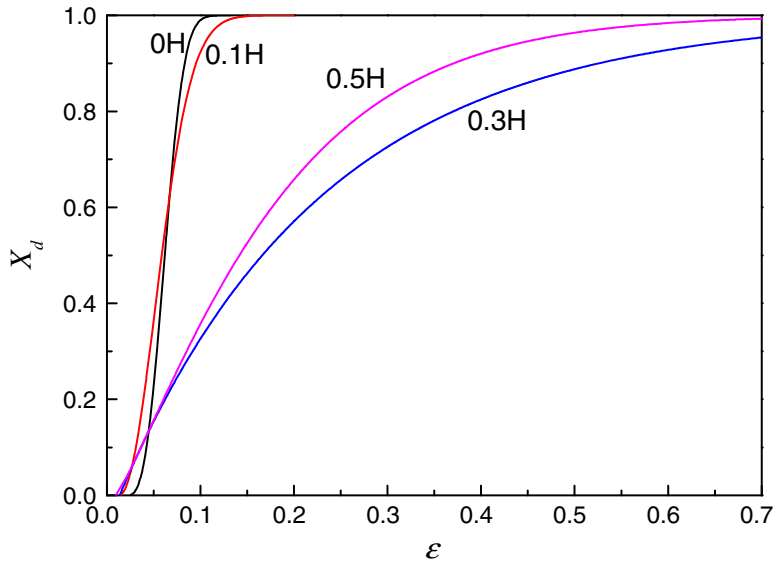

Fig. 15-Effects of hydrogen on the volume fraction of DRX at $1153 \mathrm{~K}\left(880^{\circ} \mathrm{C}\right)$ with strain rate of $0.01 \mathrm{~s}^{-1}$.

decreased strain range is observed at the hydrogen content of 0.5 pct relative to that of 0.3 pct. Complete DRX can be obtained when 0.1 pct hydrogen is added. When 0.3 and 0.5 pct hydrogen are added, however, incomplete DRX has been caused given that the highest volume fractions of DRX are obtained as 0.954 and 0.993, respectively, at the maximum strain of 0.7 .

At elevated temperature, hydrogen in solution in titanium alloys lowers the strength of dislocation interactions with various obstacles, and thus makes dislocation be activated and move easily. ${ }^{[1,6-8,29]}$ It is more difficult to reach a critical dislocation density for the nucleation of a new DRX grain in the hydrogenated specimens relative to that without hydrogen. For completing the DRX process in the hydrogenated specimens, a relatively large strain during hot deformation will be necessary in order to accumulate enough dislocations to reach a critical value to initiate the nucleation of a DRX grain. Therefore, the strain range from the initiation to the completion of DRX increases after hydrogen addition (Figure 15). When the hydrogen content is high ( 0.5 pct in this work), a short range ordering will occur. ${ }^{[1,40]}$ Although dislocation glide is expected to destroy such ordering, it may be restored continuously during deformation because of the high mobility of hydrogen. Also, the diffusibility of interstitial atoms and the grain boundary mobility will be 

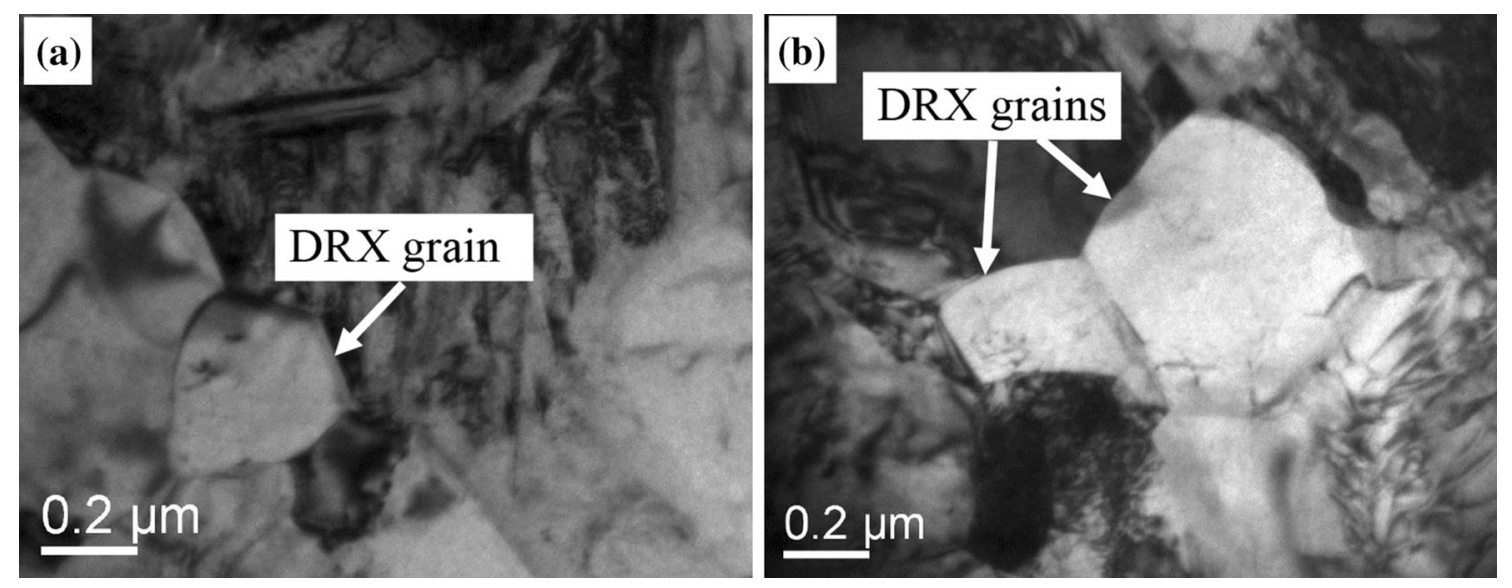

Fig. 16-TEM micrographs of the $(a) 0.3 \mathrm{H}$ and $(b) 0.5 \mathrm{H}$ specimens deformed at $1153 \mathrm{~K}\left(880{ }^{\circ} \mathrm{C}\right)$ with strain rate of $0.01 \mathrm{~s}^{-1}$.

reduced due to the occupying of numerous hydrogen atoms in the interstitial sites when the hydrogen content is high. Moreover, alloying with hydrogen increases the shear modulus of $\beta$ phase, resulting in a decrease in the density of thermally activatable dislocation sites and an increase in the heights of the barriers to glide when the hydrogen content is high. ${ }^{[41,42]}$ These factors benefit accumulating the dislocations during hot deformation and are thought to be responsible for the decreased strain range from the initiation to the completion of DRX in the $0.5 \mathrm{H}$ specimen relative to that in the $0.3 \mathrm{H}$ specimen, as shown in Figure 15.

Figure 16 shows the typical TEM micrographs of DRX grains observed in both the $0.3 \mathrm{H}$ and $0.5 \mathrm{H}$ specimens. It is clear that the addition of $0.5 \mathrm{pct}$ hydrogen seems more favorable for the occurrence of DRX relative to that after 0.3 pct hydrogen addition because higher volume fraction of DRX grains could be obtained in the $0.5 \mathrm{H}$ specimen as compared to that in the $0.3 \mathrm{H}$ specimen. Our previous study ${ }^{[6]}$ has also confirmed that the volume fraction of DRX grains in Ti600 alloy with 0.5 pet hydrogen was greater than that in Ti600 alloy with 0.3 pct hydrogen when they were deformed at $1073 \mathrm{~K}\left(800{ }^{\circ} \mathrm{C}\right)$ with a strain rate of $0.1 \mathrm{~s}^{-1}$, which is in consistence with the result displayed in Figure 15 that the volume fraction of DRX grains in the $0.5 \mathrm{H}$ specimen is higher than that in the $0.3 \mathrm{H}$ specimen after hot deformation.

\section{CONCLUSIONS}

1. The flow stress decreases gradually with hydrogen when the hydrogen content is no greater than 0.3 pct. All the flow curves exhibit a DRX characterisation. The addition of hydrogen induces fewer dislocations in the deformed matrix relative to that without hydrogen.

2. The higher the peak stress, the larger the strain to peak stress is obtained under a given temperature or strain rate. Both the peak stress and the strain to peak stress decrease gradually with hydrogen in the hydrogen range of 0 to $0.3 \mathrm{pct}$, and they both increase slightly when the hydrogen content is greater than 0.3 pct.

3. The critical stress for the initiation of DRX increases with increasing the strain rate. The higher the temperature, the lower the critical stress for the initiation of DRX is obtained. The addition of proper hydrogen (no greater than $0.3 \mathrm{pct}$ ) benefits decreasing both the critical stress and critical strain for the initiation of DRX.

4. The critical stress and critical strain for the initiation of DRX depend linearly on the peak stress and the strain to peak stress, respectively. The relationships obtained are $\sigma_{\mathrm{c}} / \sigma_{\mathrm{p}}=0.977,0.988,0.998$, and 0.995 , and $\varepsilon_{\mathrm{c}} / \varepsilon_{\mathrm{p}}=0.599,0.809,0.975$, and 0.880 for Ti600 alloy with $0,0.1,0.3$, and 0.5 pct hydrogen, respectively.

5. The strain required for the same amount of recrystallized fraction increases with decreasing the deformation temperature or increasing the strain rate. The strain range from the initiation to the completion of DRX increases gradually with hydrogen in the hydrogen range of 0 to $0.3 \mathrm{pct}$, and a slightly decreased strain range is observed at the hydrogen content of 0.5 pct relative to that of 0.3 pct. The addition of large amounts of hydrogen $(0.3$ pet or greater) in Ti600 alloy induces incomplete DRX during hot deformation.

\section{ACKNOWLEDGMENT}

The authors would like to thank Mr. Wenjing Zhang from Northeastern University, China, for assisting in the taking of optical microscope images.

\section{REFERENCES}

1. O.N. Senkov and F.H. Froes: Int. J. Hydrog. Energy, 1999, vol. 24, pp. 565-76.

2. J. Zhao, H. Ding, Y. Zhong, and C.S. Lee: Int. J. Hydrog. Energy, 2010, vol. 35, pp. 6448-54. 
3. O.N. Senkov and J.J. Jonas: Metall. Mater. Trans. A, 1996, vol. 27A, pp. 1869-76.

4. J. Zhao, H. Ding, W. Zhao, and Z. Jiang: J. Alloys Compd., 2013, vol. 574, pp. 407-14.

5. O.N. Senkov, J.J. Jonas, and F.H. Froes: JOM, 1996, vol. 48, pp. $42-47$.

6. J.W. Zhao, H. Ding, H.L. Hou, and Z.Q. Li: J. Alloys Compd., 2010, vol. 491, pp. 673-78.

7. J.W. Zhao, H. Ding, Y.Q. Wang, and H.L. Hou: Trans. Nonferrous Met. Soc. China, 2009, vol. 19, pp. 65-71.

8. Y.Y. Zong, D.B. Shan, Y. Lü, and B. Guo: Int. J. Hydrog. Energy, 2007, vol. 32, pp. 3936-40.

9. Y. Niu, H. Hou, M. Li, and Z. Li: Mater. Sci. Eng. A, 2008, vol. 492, pp. 24-28.

10. Q.J. Sun, G.C. Wang, and M.Q. Li: Mater. Des., 2012, vol. 35, pp. $80-86$.

11. X. Zhang, Y. Zhao, and W. Zeng: In. J. Hydrogen Energy, 2010, vol. 35, pp. 4354-60.

12. Y. Zong, S. Huang, Y. Feng, and D. Shan: J. Alloys Compd., 2012, vol. 541, pp. 60-64.

13. M.Q. Li, J. Luo, and Y. Niu: Mater. Sci. Eng. A, 2010, vol. 527, pp. 6626-32.

14. W.P. Sun and E.B. Hawbolt: ISIJ Int., 1997, vol. 37, pp. 1000-09.

15. E.I. Poliak and J.J. Jonas: Acta Mater., 1996, vol. 44, pp. 127-36.

16. M.R. Barnett, G.L. Kelly, and P.D. Hodgson: Scripta Mater., 2000, vol. 43, pp. 365-69.

17. G. Gottstein, M. Frommert, M. Goerdeeler, and N. Schafer: Mater. Sci. Eng. A, 2004, vols. 387-389, pp. 604-08.

18. E.I. Poliak and J.J. Jonas: ISIJ Int., 2003, vol. 43, pp. 684-91.

19. J.J. Jonas and E.I. Poliak: Mater. Sci. Forum, 2003, vols. 426-432, pp. 57-66.

20. M. Shaban and B. Eghbali: Mater. Sci. Eng. A, 2010, vol. 527, pp. 4320-25.

21. H. Mirzadeh and A. Najafizadeh: Mater. Des., 2010, vol. 31, pp. 1174-79.

22. Y.F. Xia, Y.Y. Liu, Y.P. Mao, G.Z. Quan, and J. Zhou: Trans. Nonferrous Met. Soc. China, 2012, vol. 22, pp. S668-72.

23. G.Z. Quan, Y.P. Mao, G.S. Li, W.Q. Lv, Y. Wang, and J. Zhou: Comput. Mater. Sci., 2012, vol. 55, pp. 65-72.

24. A. Galiyev, R. Kaibyshev, and G. Gottstein: Acta Mater., 2001, vol. 49, pp. 1199-1207.
25. J. Zhao, H. Ding, Z. Jiang, M. Huang, and H. Hou: Mater. Des., 2014, vol. 54, pp. 967-72.

26. J. Zhao, H. Ding, W. Zhao, H. Xiao, H. Hou, and Z. Li: Chinese J. Mater. Res., 2008, vol. 22, pp. 262-68.

27. J.W. Zhao, H. Ding, W.J. Zhao, X.F. Tian, H.L. Hou, and Y.Q. Wang: Trans. Nonferrous Met. Soc. China, 2008, vol. 18, pp. 50611 .

28. Y. Han, W. Zeng, Y. Qi, and Y. Zhao: Mater. Sci. Eng. A, 2011, vol. 528, pp. 8410-16.

29. J. Zhao: Influence of Thermo Hydrogen Treatment on Microstructural Evolution and High Temperature Deformation Behaviour of Titanium Alloys, Northeastern University, Shenyang, 2009.

30. D.L. Ouyang, S.Q. Lu, X. Huang, and L.M. Lei: Chin. J. Nonferrous Met., 2010, vol. 20, pp. 1539-44.

31. P. Vo, M. Jahazi, and S. Yue: Metall. Mater. Trans. A, 2008, vol. 39A, pp. 2965-80.

32. F.J. Humphreys and M. Hatherly: Recrystallization and Related Annealing Phenomena, 2nd ed., Pergamon Press, Oxford, 2004.

33. R. Ding and Z.X. Guo: Acta Mater., 2001, vol. 49, pp. 3163-75.

34. S.E. Kulkova, A.V. Bakulin, S.S. Kulkov, S. Hocker, and S. Schmauder: J. Exp. Theor. Phys., 2012, vol. 115, pp. 462-73.

35. A.A. Ilyin, A.M. Mamonov, V.K. Nosov, and V.M. Majstrov: Russ. Metall., 1994, vol. 5, pp. 74-77.

36. L.X. Kong, P.D. Hodgson, and B. Wang: J. Mater. Process. Technol., 1999, vols. 89-90, pp. 44-50.

37. C.X. Yue, L.W. Zhang, S.L. Liao, J.B. Pei, H.J. Gao, Y.W. Jia, and X.J. Lian: Mater. Sci. Eng. A, 2009, vol. 499, pp. 177-81.

38. T. Seshacharyulu, S.C. Medeiros, J.T. Morgan, J.C. Malas, W.G. Frazier, and Y.V.R.K. Prasad: Mater. Sci. Eng. A, 2000, vol. 279, pp. 289-99.

39. H.J. McQueen and D.L. Bourell: in Formability and Metallurgical Structures, A.K. Sachdev and J.D. Embury, eds., TMS, Warrendale, PA, 1986, pp. 2123-30.

40. A.D. McQuillan: Proc. R. Soc. Lond. Ser. A, 1950, vol. 204, pp. 309-23.

41. O.N. Senkov, M. Dubois, and J.J. Jonas: Metall. Mater. Trans. A, 1996, vol. 27A, pp. 3963-70.

42. O.N. Senkov and J.J. Jonas: in Hot Workability of Steels and Light Alloys-Composites, H.J. McQueen, E.V. Konopleva, and N.D. Ryan, eds., Montreal, QC, 1996, pp. 259-66. 